\title{
The Effect of Longitudinal Rails on an Air Cavity Stepped Planing Hull
}

\author{
Filippo Cucinotta ${ }^{1, *(\mathbb{D})}$, Dario Mancini ${ }^{2}$, Felice Sfravara ${ }^{1}$ and Francesco Tamburrino ${ }^{3}$ (D) \\ 1 Department of Engineering, University of Messina, Contrada Di Dio (S. Agata), 98166 Messina, Italy; \\ fsfravara@unime.it \\ 2 Istituto Nazionale di Astrofisica-Osservatorio Astronomico di Capodimonte, 80131 Naples, Italy; \\ dario.mancini@inaf.it \\ 3 Department of Civil and Industrial Engineering, University of Pisa, Largo Lucio Lazzarino 1, 56122 Pisa, Italy; \\ francesco.tamburrino@ing.unipi.it \\ * Correspondence: filippo.cucinotta@unime.it; Tel.: +39-0906765292
}

Citation: Cucinotta, F.; Mancini, D.; Sfravara, F.; Tamburrino, F. The Effect of Longitudinal Rails on an Air Cavity Stepped Planing Hull. J. Mar. Sci. Eng. 2021, 9, 470. https:// doi.org/10.3390/jmse9050470

Academic Editor:

Apostolos Papanikolaou

Received: 22 March 2021

Accepted: 25 April 2021

Published: 27 April 2021

Publisher's Note: MDPI stays neutral with regard to jurisdictional claims in published maps and institutional affiliations.

Copyright: (c) 2021 by the authors. Licensee MDPI, Basel, Switzerland. This article is an open access article distributed under the terms and conditions of the Creative Commons Attribution (CC BY) license (https:/ / creativecommons.org/licenses/by/ $4.0 /)$.
Abstract: The use of ventilated hulls is rapidly expanding. However, experimental and numerical analyses are still very limited, particularly for high-speed vessels and for stepped planing hulls. In this work, the authors present a comparison between towing tank tests and CFD analyses carried out on a single-stepped planing hull provided with forced ventilation on the bottom. The boat has identical geometries to those presented by the authors in other works, but with the addition of longitudinal rails. In particular, the study addresses the effect of the rails on the bottom of the hull, in terms of drag, and the wetted surface assessment. The computational methodology is based on URANS equation with multiphase models for high-resolution interface capture between air and water. The tests have been performed varying seven velocities and six airflow rates and the no-air injection condition. Compared to flat-bottomed hulls, a higher incidence of numerical ventilation and air-water mixing effects was observed. At the same time, no major differences were noted in terms of the ability to drag the flow aft at low speeds. Results in terms of drag reduction, wetted surface, and its shape are discussed.

Keywords: computational fluid dynamics; hull design; air cavity ships; hull ventilation; stepped planing hull

\section{Introduction}

The drag reduction is the main issue in limiting fuel consumption or enhancing the performance of High Speed Vessels (HSV). Traditionally the global drag is divided into two principal components: wave-making drag and viscous drag [1]. Under the name of viscous drag are included all the effects due to the fluid viscosity, i.e., all the effects that would be zero if the fluid is inviscid. The viscous part affects several phenomena, including the so-called form effect, the friction effect, the roughness, and the flat plate friction. According to the ship typology and its Froude number, the resistance can change from about $40 \%$ to $95 \%$ of the global resistance [2]. Over time, there have been numerous attempts to reduce the drag's viscous component, including the use of multihull, the Surface Effect Ships, the use of foils (to reduce the wet surface), or the use of hull ventilation [3]. From the first experiments to today, there have been many efforts to exploit the effect of the ventilation for drag reduction. Hull ventilation can be addressed both in a natural or forced manner. The presence of an air pocket can also have a lift role or only a lubricating effect. The shape or the mass of air can be in the form of cushion [4], layer [5], bubbles, or microbubbles [6].

In order to exploit natural ventilation of planing hulls, wedge boats and stepped bottom were theorized and studied, both experimentally and numerically, since the forerunners' work of Savitsky [7]. In fact, the planing hulls behave in a similar way to an 
airfoil. In this way, the natural under pressure generated behind a step can be exploited to facilitate the entry and diffusion of air for ventilating the bottom.

Dashtimanesh et al. dealt with multistep hulls suggesting empirical methods [8] and by the CFD approach $[9,10]$. De Marco et al. tried the Large Eddy Simulations (LES) approach, with different moving mesh techniques [11]. Niazmand Bilandi et al. applied the $2 \mathrm{D}+\mathrm{T}$ theory with success, extending $2 \mathrm{D}$ theory to tridimensional problems at doublestepped planing hulls $[12,13]$. The results have been furthermore applied to laboratory experiments and mathematical modeling [14]. In the range of experimental studies, the studies of systematic variations in a series of stepped hull are particularly interesting, such as the works of Lee et al. [15] and of Taunton et al. [16].

Butuzov et al. were pioneers in the concept of modern forced ventilated hulls [17]. Since then, many authors have carried out numerical and experimental studies on Air Cavity Ships (ACS) and Air Cushion Vehicles (ACV). Mäkiharju et al. studied the problem of scaling air behavior from model to real scale [18]. A great contribution to this topic comes from Matveev's research who studied a two-dimensional [19] and three-dimensional [20] approach. In 2015, Butterworth carried out experimental campaigns on a container ship [21], while in 2017, Cucinotta et al. performed an experimental campaign on three different planning models and a mother hull [22]. Wang et al. carried out experimental tests obtaining similar results and finding excellent performances in terms of porpoising [23]. Barbaca et al. [24] and Qin et al. [25] focused their attention on the cavity flow, taking advantage of cavity growth, shedding, and closure characteristics.

A tool that has made it possible to achieve significant research progress in this field is Computational Fluid Dynamic (CFD). This made it possible to reduce research times and costs, overcome scale problems, and better monitor the phenomena under the hull [26]. Hull [27] and foils [28] fluid dynamics can be addressed successfully by implementing CFD analyses. Furthermore, it is possible to implement the calculus with Fluid Structure Interaction analysis (FSI) [29] and optimization analysis [30].

By means of CFD, Cucinotta et al. simulated the hydrodynamics of two models, [31] and [32], validating them through experimental data. In these analyses, the authors showed good results regarding drag reduction and numerical convergence and reliability. Since air, as has been widely observed, tends to escape from the hull sides, especially at low speeds, the attempt to use longitudinal rails to contain the air flow has been proposed and assessed in this work. Therefore, the authors present the results of experimental tests and CFD analyses carried out on a model identical with that presented in [22] but with the addition of longitudinal rails within the stepped part of the hull and assess their evaluation.

The article is structured in a first part, which describes in depth the used methods, firstly of the experimental campaign and secondly of the CFD campaigns, and in a second part that shows the results and the relative comments. Finally, after the conclusions, a list of nomenclature is reported.

\section{Methods}

The chapter describes the geometric characteristics of the hull and the position of the step for the injection of the air and the geometric dimensions of the rails. In order to have a general idea of the line of the hull, a lines plan is proposed and the trend of the transversal section area is reported for the sake of completeness. The second part of this chapter introduces the simulation settings. The mesh and the refinement zones are presented and a complete description of the sequence of simulations conducted allows us to understand the approach used during this campaign of investigation. Particular attention concerns the methodology used for the wall-treatment inside the commercial CFD software and the initial boundary conditions.

\subsection{The Model}

As reported in [33], the original yacht is $18 \mathrm{~m}$ in length and whose principal dimensions are reported by Cucinotta et al. [22]. 
The bottom part of the hull was modified in order to have a step for injection of the air. A series of rails from the step to the transom was added. The model is fully described by [22] and for the sake of readability, the main dimensions are reported in Table 1.

Table 1. Main dimensions.

\begin{tabular}{lccc}
\hline \multicolumn{1}{c}{ Dimensions } & Ship & Model & Unit \\
\hline $\mathrm{LWL}$ & 14.884 & 2.481 & $\mathrm{~m}$ \\
$\mathrm{LP}$ & 16.2 & 2.7 & $\mathrm{~m}$ \\
$\mathrm{BWL}$ & 4.314 & 0.719 & $\mathrm{~m}$ \\
$\mathrm{BPX}$ & 3.72 & 0.62 & $\mathrm{~m}$ \\
$\mathrm{BPA}$ & 3.2 & 0.54 & $\mathrm{~m}$ \\
$\mathrm{BPT}$ & 3.66 & 0.61 & $\mathrm{~m}$ \\
$\mathrm{~T}$ & 1.000 & 0.167 & $\mathrm{~m}$ \\
$\mathrm{~S}$ & 34 & 0.153 & $\mathrm{t}$ \\
$\mathrm{S}$ & 78.6 & 2.182 & $\mathrm{~m}^{2}$ \\
$\mathrm{x}_{\mathrm{G}}(\%$ of LOA $)$ & $35.92 \%$ & $35.92 \%$ & - \\
$\mathrm{AP}$ & 52.2 & 1.45 & $\mathrm{~m}^{2}$ \\
$\mathrm{~N}_{\mathrm{ST}}$ & 1 & 1 & - \\
$\mathrm{L}_{\mathrm{ST}}$ & 8.00 & 1.333 & $\mathrm{~m}$ \\
$\mathrm{~S}_{\mathrm{ST}}$ & 0.304 & 0.0084 & $\mathrm{~m}^{2}$ \\
$\mathrm{~N}_{\mathrm{IN}}$ & 10 & 10 & - \\
$\mathrm{B} \times \mathrm{H}$ & $0.31 \times 0.09$ & $0.051 \times 0.015$ & $\mathrm{~m}^{2} \mathrm{~m}$ \\
$\mathrm{~S}_{\mathrm{IN}}$ & 0.279 & 0.0077 & $\mathrm{~m}^{2}$ \\
\hline & Longitudinal Rails & Dimensions & \\
\hline $\mathrm{N}$ & 8 & 8 & $\mathrm{~m} \times \mathrm{m}$ \\
$\mathrm{B}_{\mathrm{R}} \times \mathrm{H}_{\mathrm{R}}$ & $0.041 \times 0.059$ & $0.007 \times 0.01$ & $\mathrm{~m}$ \\
$\mathrm{TD}$ & 0.340 & 0.056 & \\
\hline
\end{tabular}

Figure 1 shows the linesplane, with the presence of the step and its position with respect to the transom. The step is located $8 \mathrm{~m}$ away from the transom $(1.33 \mathrm{~m}$ for the scale model) and the rails starting from this step until the end of the hull. The presence of the step produces a discontinuity in the transversal section area of about $0.3 \mathrm{~m}^{2}$.
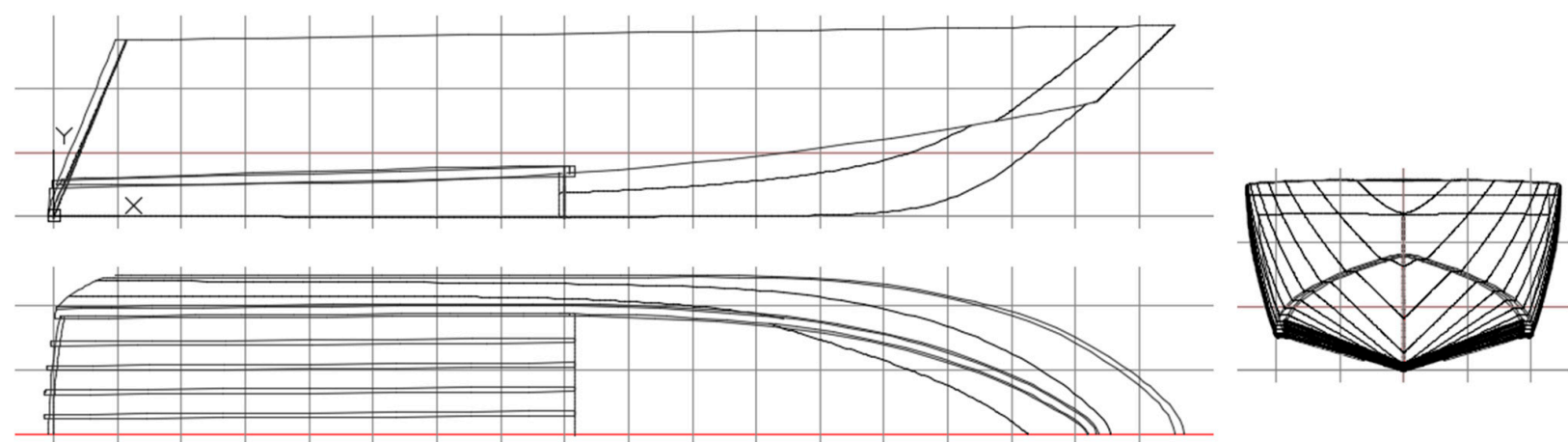

Figure 1. Multi-Step hull-Position of rails.

The experimental campaign was carried out in the University of Naples facilities and the results are reported in [22]. Figures 2 and 3 and show, respectively, the bottom of the model and a picture from the tests in the towing tank. 


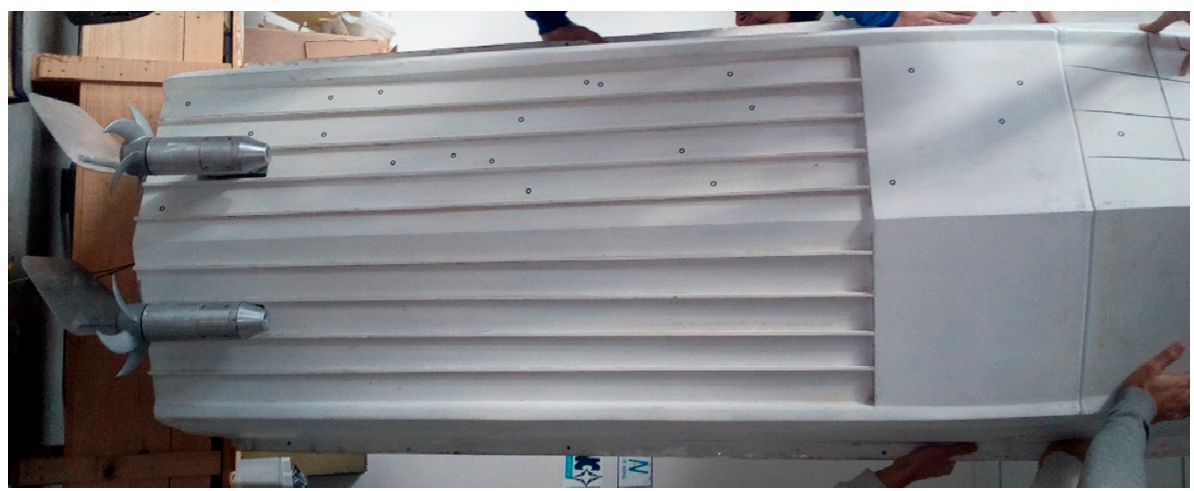

Figure 2. The bottom of the hull.

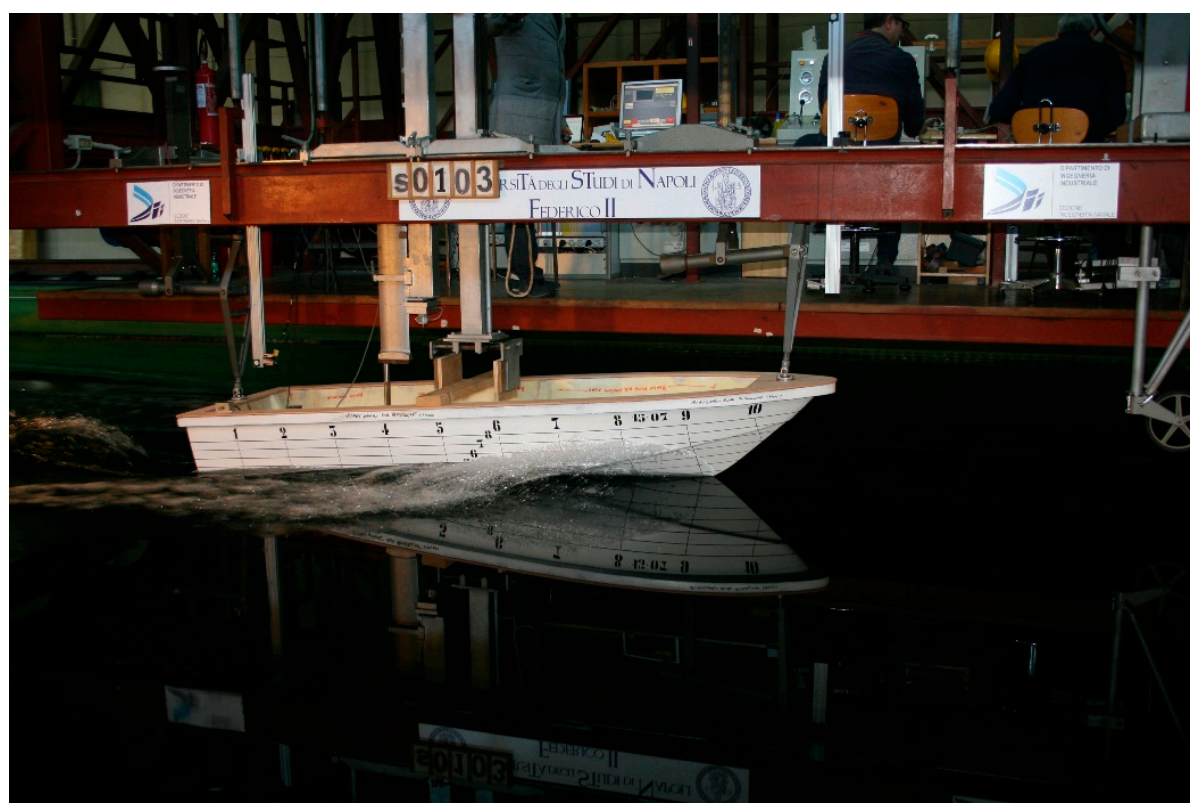

Figure 3. A test in towing tank.

\subsection{Simulation Settings}

The approach used for solving the fluid dynamics around the hull is the Computational Fluid Dynamic (CFD in this paper). The main goal of simulation is to solve the pressure and velocity field around the hull, the volume fraction (the interface between the air and the water), and, finally, the relative position of the boat in terms of trim and sinkage. In order to capture all characteristics of the fluid field in terms of pressure and velocity, a URANSE (Unsteady RANS) approach was chosen. This approach allows to use the Navier-Stokes equations to solve all the unknowns of fluid. The finite volume method is implemented in the commercial software STAR CCM+ [34] used for this campaign of simulations. A crucial parameter is the time-step and the discretization order of the scheme used (in this simulation 2nd order) for the time-marching solution. The ITTC [35] suggests using a time-step in a range given by a function of the length of the hull and velocity of the boat, according to the formula

$$
\Delta t=0.01 \div 0.05 \frac{l}{v}
$$

in which $l$ is the length and $v$ the velocity of the boat. A complete uncertainty analysis that comprises the evaluation of time step size, Courant number, grid dimension, and convergence ratio was carried out according to [35]. The detailed results are reported in [31]. 
The complexity of the simulation is due to the interaction between water and air in two different ways (interface of the sea, injection of the air in the bottom of the hull). Both fluids are treated as incompressible.

The multiphase simulation, with the VoF (Volume of Fluid) scheme, is used and thanks to the High-resolution interface capturing scheme (HRIC), a clear interface is captured during the entire duration of the simulation. A surface tension equal to $0.072 \mathrm{~N} / \mathrm{m}$ between the two fluids is imposed. All the solver settings are the same as the ones used by Cucinotta et al. [31]. However, for the sake of clarity, Table 2 reports all the settings used during the simulation.

Table 2. Settings.

\begin{tabular}{ll}
\hline \multicolumn{1}{c}{ Discretization Method } & \multicolumn{1}{c}{ Finite Volume Method } \\
\hline Solver & Implicit Unsteady \\
Approach & Segregated Flow \\
Continuity and Momentum Equation coupling & SIMPLE-Algorithm \\
Convection Term & 2nd Order \\
Turbulence Model & k-Omega Menter \\
Surface tension & CSF model \\
Temporal Discretization & 2nd order \\
Iteration for Time Step & 10 \\
Time Step & Equation (1) \\
Gradient Discretization & Hybrid Gauss-LSQ \\
Algebraic system of Equations solver & AGM-Algebraic Multigrid Solver \\
Interface & VoF-Volume of Fluid \\
Convection Scheme for VoF & HRIC-High-Resolution Interface Capturing \\
Ship hull motion & DBI-Dynamic Fluid Body Interaction \\
Inner Iterations for Ship Motion & 10 \\
Mesh motion & Overset Mesh \\
Interpolation for Overset & Linear \\
\hline
\end{tabular}

In addition to the multiphase problem, the simulation also solves the motion of the boat. The approach used is the overset mesh. It helps to keep the quality of mesh very high. In order to use this procedure, the model was divided into two different regions: the background region (the fixed region in the space) and the overset region. The latter is free to move along the Z-axis (axis perpendicular to initial free-surface) and it is free to rotate itself along the $Y$-axis. The method used for solving the motion of the boat is the DFBI (Dynamic Fluid Body Interaction). It allows to solve the flow around a rigid body and simultaneously the motion of the rigid body caused by external forces and the forces induced by the flow (viscous forces, pressure forces). The equations of motion are the classic rigid body equations. For each step, the Navier-Stokes equations are solved considering the volume fraction under the hull by means VoF model. The viscous effects and the pressure field are integrated over the vessel in order to obtain the value of forces and moments. In function of these quantities, the solver applies the rigid body equations considering as center of motion the center of gravity of the boat. Finally, considering all the effects solved thanks to Navier-Stokes equations and Vof method (turbulence, air under the hull, waves, pressure field around the hull, viscous effects), the position, velocity, and acceleration of the boat is updated.

The geometry was defined with the commercial CAD software and all lines of the hull were defined with the higher precision possible (NURBS modeling). The ITTC [35] defines a series of guidelines in order to do a virtual towing tank. All these dimensions are shown in Figure 4. 


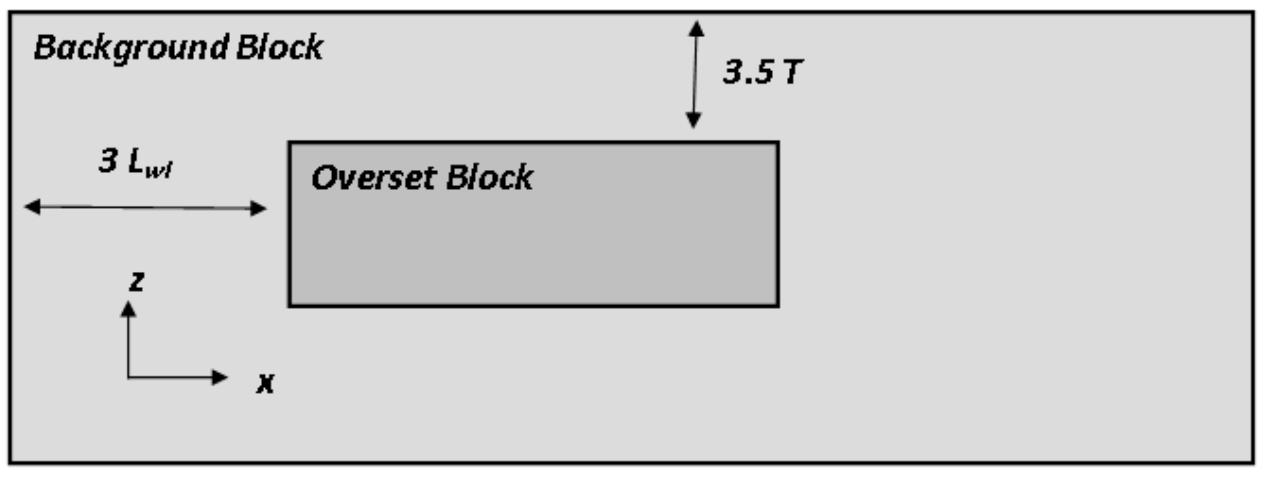

Figure 4. Overset and Background regions.

\subsection{Boundary Conditions and Mesh}

Figure 5 shows the background block with all the boundary conditions defined inside the solver. Each boundary condition is a field function that involves the velocity and pressure component of the fluid. The inlet has a Velocity Field function, it considers the position of the free surface and the velocity of the boat. The free surface is an unknown quantity that is solved each time step. The hidden surface is defined as symmetry in order to simulate only half of the domain. The outlet surface has a pressure boundary condition. It helps to update the free surface also in the outlet.

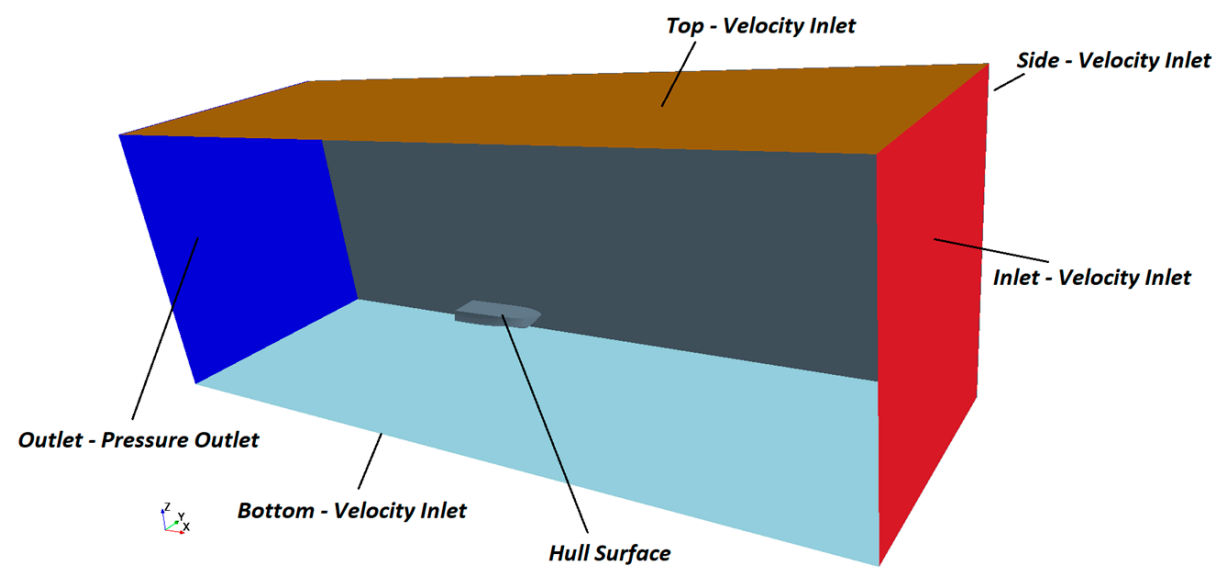

Figure 5. Boundary conditions.

In the overset region, the external surfaces are the ones linked with the background region. A zone where it is possible to have problems during the simulation is the overlapping zone between overset and background. There is a gap of elements where the solver exchanges the results of the corresponding zones; it is crucial to have a size of mesh very similar in this gap to avoid overflow errors. The blue surface is the symmetry area and the hull in grey is a wall no-slip surface. The step for injection of the air is a wall in no-slip condition (simulation is without air injection) and Inlet mass flow when the simulation involves the air injection.

The trimmed cartesian mesh process is used for this simulation. This approach allows defining different blocks for refinement. As shown in Figure 6, the refinement is conducted to keep a low aspect ratio and capture physics phenomena of different zones of interest. It is evident that a clear refinement is inside the overset block, in the free-surface zone, and the area around the boat with the Kelvin triangle (Figure 7). 


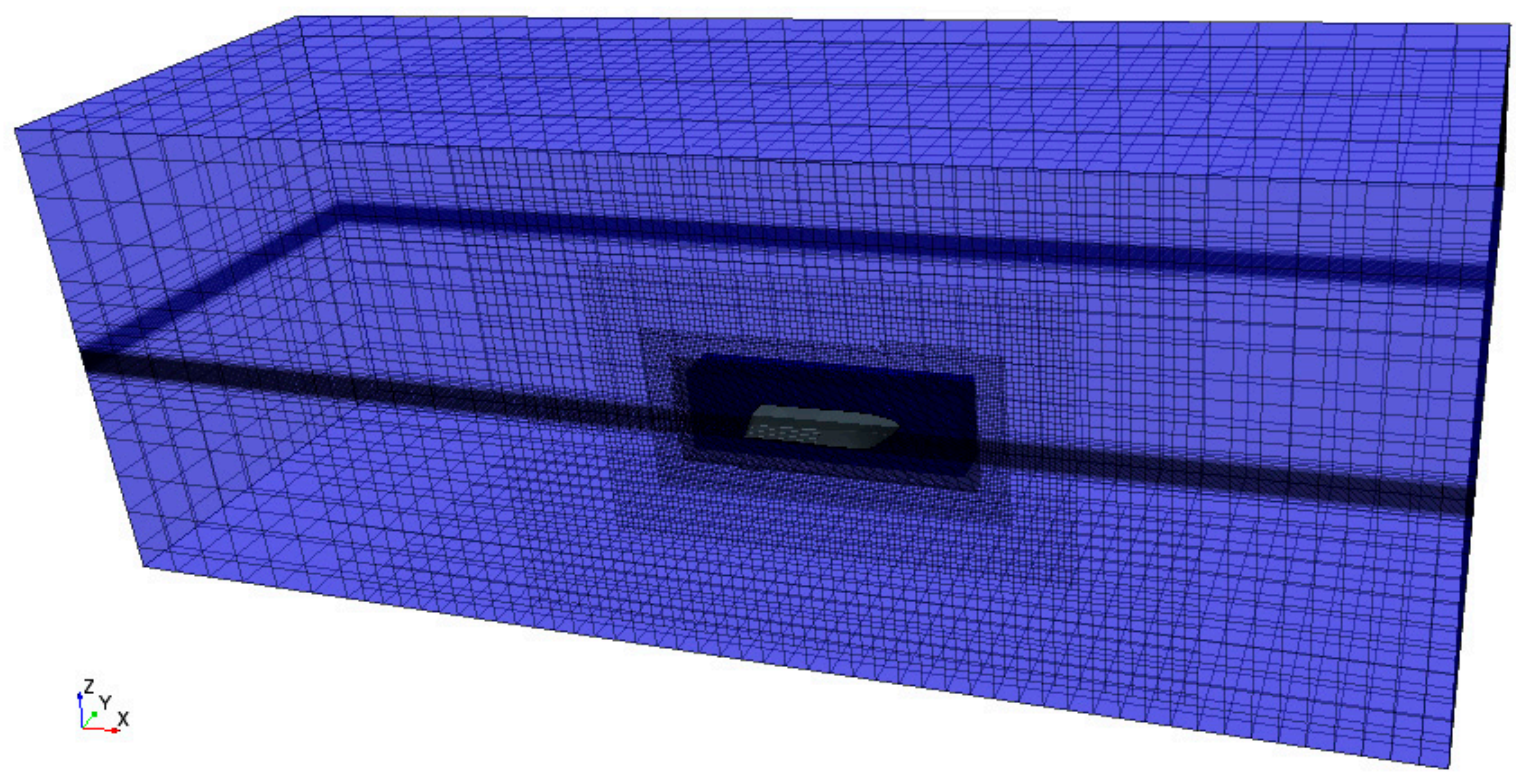

Figure 6. Mesh in all regions of the simulation. It is possible to notice the overset refinement.

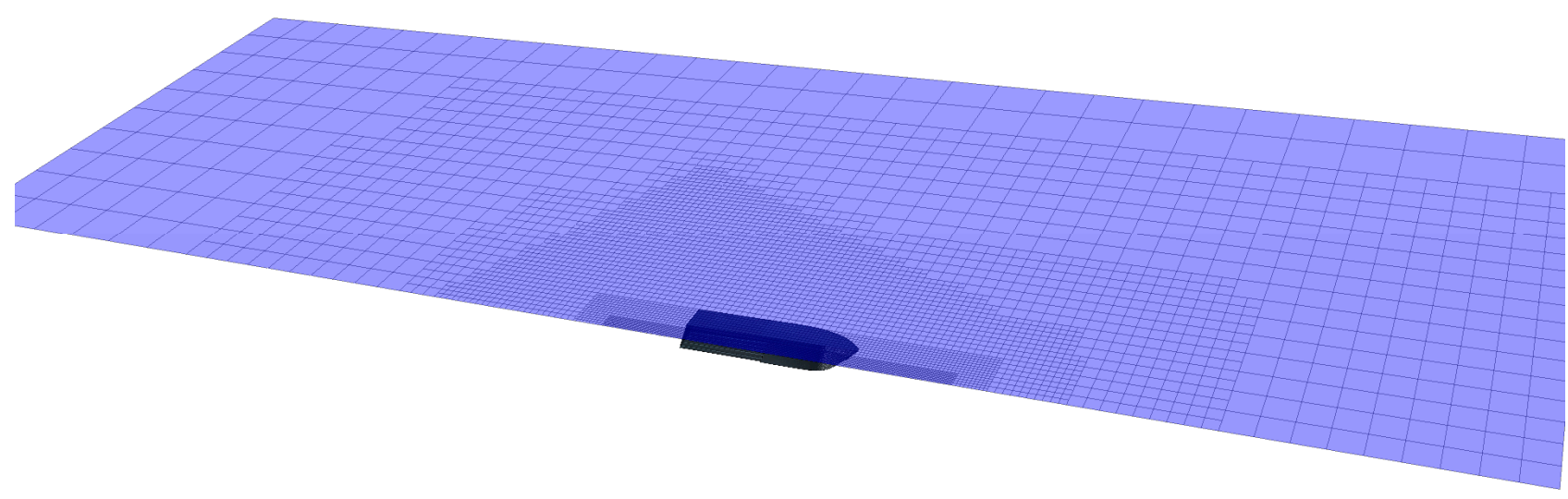

Figure 7. Kelvin refinement.

The hull has meshed with particular attention to the immersed zone (Figure 8). The rails were captured by the mesh with a local refinement, this increases the number of elements of the mesh. The total number of cells for the overset zone is $4.57 \mathrm{Mln}$ and for the background zone is $0.49 \mathrm{Mln}$.

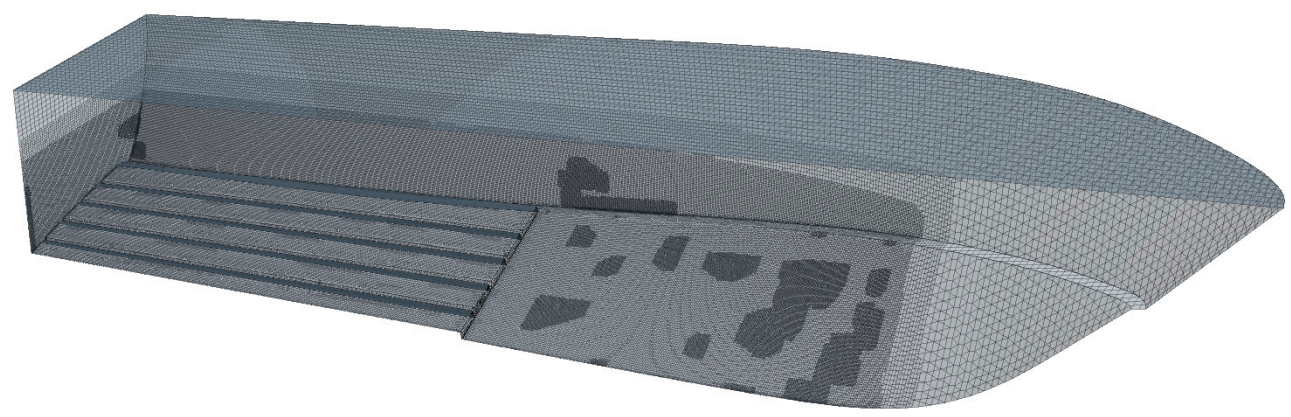

Figure 8. Hull refinement. 
The wall surface of the hull has meshed with a prism layer of elements that allows capturing the boundary layer appropriately. The parameter that the authors keep under control is the Wall $\mathrm{y}+$ that for all simulations is always between 30 and 200 (Figure 9).

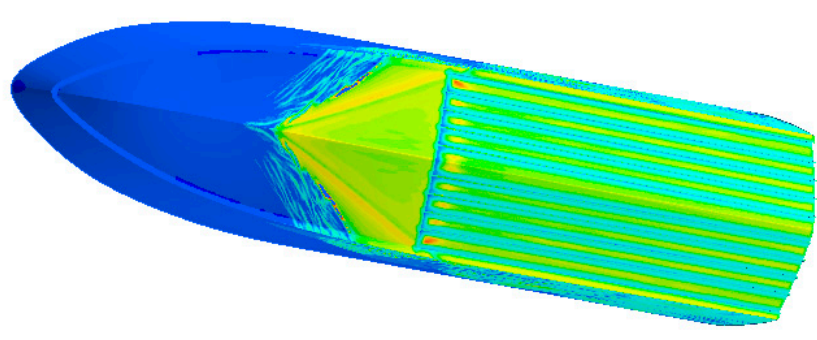

$x z^{Y}$

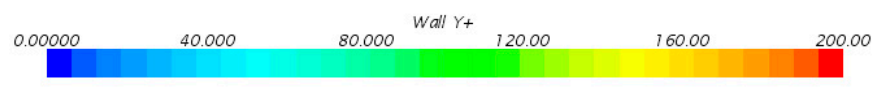

Figure 9. Wall $\mathrm{y}+$ at full speed.

Finally, thanks to CFD, it is possible to know the area of hull wetted by the water or by the air. It is possible to solve this quantity considering a cut-off method on the volume fraction. The wetted surface by the water is calculated defining an interval of volume fraction where the hull is considered wet by the water. In this work, the chosen threshold was a volume fraction comprises between 0.5 and 1 . The solver integrates the area where there are these values of water fraction and so evaluate the amount of hull wetted by the water.

\subsection{Simulations Campaign}

The simulations were conducted in two different parts. The first part involves the construction of the resistance curve in function of the velocity without the injection of the air. These results will be compared with experimental tests. During the simulation, the trend of the main physic quantities (drag, trim, and sinkage) was plotted and when these curves reached a stable condition, the simulation was over.

The velocities under investigation are the same as the experimental tests conducted and reported by Cucinotta et al. [22]. From the first campaign, the recorded pressure and velocity fields of the fluid and the relative position of the yacht in terms of trim and sinkage to each Froude number were recorded. These steady states became the initial conditions of the transient simulation of the second campaign. This methodology helps the convergence and the speed of the calculus.

During the first campaign of simulation, an uncertainty analysis has been conducted following the methodology proposed by ITTC [35]. The total uncertainty can be divided in three different terms: iterative $\left(\mathrm{U}_{\mathrm{I}}\right)$, grid $\left(\mathrm{U}_{\mathrm{G}}\right)$, and time-step uncertainties $\left(\mathrm{U}_{\mathrm{T}}\right)$. Stern et al. [36] suggested that the value of uncertainty caused by the grid is an order of magnitude greater than other ones and it is recommended for each simulation to evaluate this value of uncertainty. The method consists in evaluating several $\mathrm{n}$-th physic quantities $\left(S_{n 1}, S_{n 2}\right.$, and $S_{n 3}$ ) to three different meshes (1 fine mesh, 2 medium mesh, 3 coarse mesh) with a constant ratio between number of cells $\left(r_{k}\right)$ (see Table 3 ). In this case, the physic quantities assessed are Drag, Trim, Sinkage, and Wetted Surface. For each parameter chosen, it can be calculated the difference between medium-fine mesh (2) and between coarse-medium mesh (3). Thanks to these values, it is possible to evaluate the convergence ratio $R_{G}(4)$ and the order of accuracy $P_{G}(5)$. 
Table 3. Convergence ratio.

\begin{tabular}{cc}
\hline Value of Convergence Ratio & Type of Convergence \\
\hline $0<R_{G}<1$ & Monotonic \\
$R_{G}<0 \&\left|R_{G}\right|<1$ & Oscillatory \\
$R_{G}>1$ & Monotonic divergence \\
$R_{G}<0 \&\left|R_{G}\right|>1$ & Oscillatory divergence \\
\hline
\end{tabular}

Finally, with these two values it is possible to obtain the uncertainty with the Richardson formulation (6).

$$
\begin{gathered}
\varepsilon_{n 21}=S_{n 2}-S_{n 1}, \\
\varepsilon_{n 32}=S_{n 3}-S_{n 2}, \\
R_{G}=\frac{\varepsilon_{n 21}}{\varepsilon_{n 32}}, \\
P_{G}=\frac{\ln \left(\frac{\varepsilon_{n 32}}{\varepsilon_{n 21}}\right)}{\ln r_{k}} . \\
U_{n}=F_{S}\left|\frac{\varepsilon_{n 21}}{R_{G}^{P_{G}}-1}\right|
\end{gathered}
$$

The main objective of this part is to define the reduction of resistance with the injection of the air. The flow rates analyzed were generally ranging from $5500 \mathrm{~L} / \mathrm{min}$ (liter per minute) to $10,500 \mathrm{~L} / \mathrm{min}$, with a step of $1000 \mathrm{~L} / \mathrm{min}$. The Froude number studied were between 0.64 and 0.89 and from 5500 to 10,500 L/min for the Froude number between 1.02 and 1.36. Only for low Froude numbers the same high flowrate was not tested, since the difference between low and high flowrate became negligible.

The total number of conditions analyzed is 28. Another important objective of this campaign of simulation is the distribution of the air under the hull during the the air injection. The conditions that were simulated are briefly summarized in Table 4.

Table 4. Velocities and time-step used for the simulations.

\begin{tabular}{cccccccc}
\hline & \multicolumn{3}{c}{ First Part of Simulation } & \multicolumn{3}{c}{ Second Part of Simulation } \\
\hline $\mathbf{V}_{\mathbf{M}}[\mathbf{m} / \mathbf{s}]$ & Fn & $\boldsymbol{\Delta}_{\boldsymbol{t}}[\mathbf{s}]$ & Two-Steps & $\begin{array}{c}\text { Interval of Flow Rate } \\
{[\mathbf{L} / \mathbf{m i n}]}\end{array}$ & $\begin{array}{c}\text { Step Flow } \\
\text { Rate [L/min] }\end{array}$ & $\boldsymbol{\Delta}_{\boldsymbol{t}}[\mathbf{s}]$ & Two-Steps \\
\hline 3.15 & 0.64 & 0.01 & Wall-No slip & $5500-8500$ & 1000 & 0.005 & Air Flow Inlet \\
3.78 & 0.76 & 0.01 & Wall-No slip & $5500-8500$ & 1000 & 0.005 & Air Flow Inlet \\
4.41 & 0.89 & 0.01 & Wall-No slip & $5500-8500$ & 1000 & 0.005 & Air Flow Inlet \\
5.04 & 1.02 & 0.01 & Wall-No slip & $5500-10,500$ & 1000 & 0.005 & Air Flow Inlet \\
5.67 & 1.15 & 0.01 & Wall-No slip & $5500-10,500$ & 1000 & 0.005 & Air Flow Inlet \\
6.30 & 1.27 & 0.01 & Wall-No slip & $5500-10,500$ & 1000 & 0.005 & Air Flow Inlet \\
6.72 & 1.36 & 0.01 & Wall-No slip & $5500-10,500$ & 1000 & 0.005 & Air Flow Inlet \\
\hline
\end{tabular}

\subsection{Hardware}

All the operational phases described were conducted on a workstation with an Intel Xeon 2 GHz, 2 CPU with 16 core, 36 GB of memory, and a Nvidia Quadro M5000 8 GB.

\section{Results}

\subsection{Results of the First Part of the Simulation}

The first part of the simulation concerns the model without air injection. The curves of resistance, trim, and sinkage were compared with the ones of experimental tests. In adding to this information, the other purpose of this block of simulations is to have a starting point for the next campaign of simulation. Figure 10 shows the comparison between 
experimental and numerical simulation. The maximum difference between the two curves is to the maximum velocity.

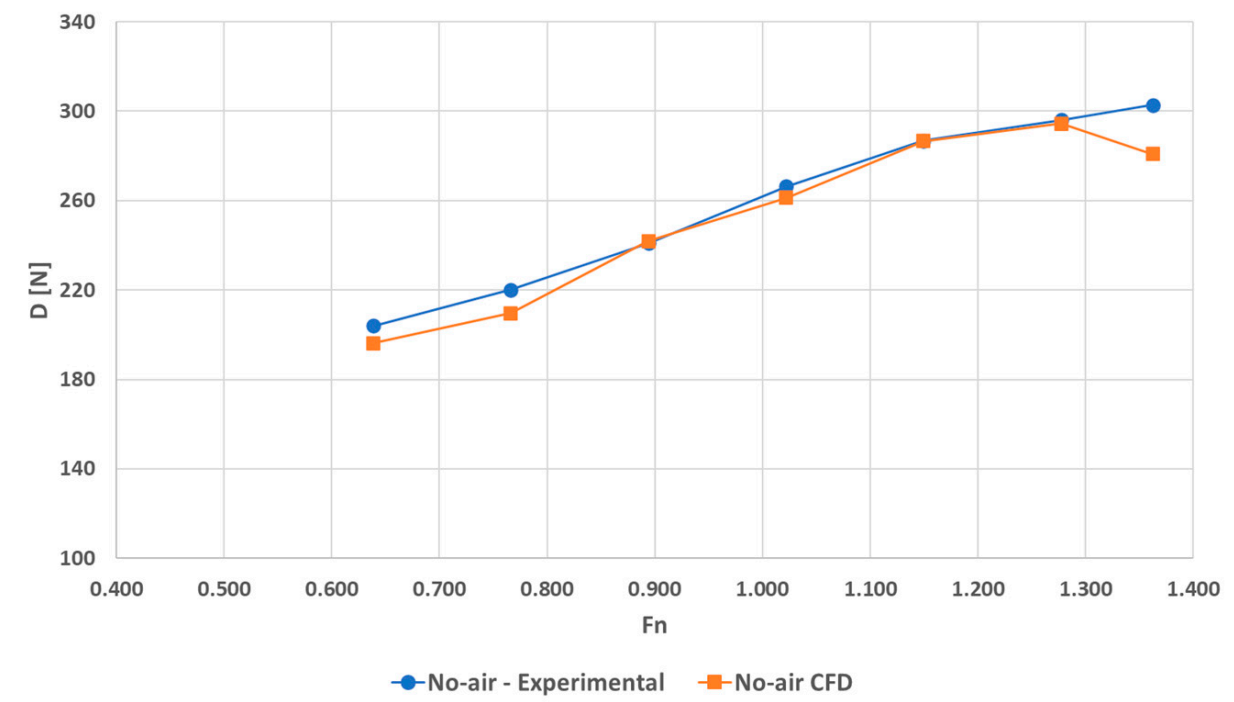

Figure 10. Resistance curves comparison.

Usually, the increase of velocity could lead to a higher probability of numerical ventilation effect. This effect is caused by two main reason: the VoF method, at high Fn and with an overset mesh [37], and the planing hull characteristics (the acute angle caused by the intersection between the hull and the free-surface) [38]. Even if this phenomenon is known and studied, there are very few specific studies on a problem as complex as that relating to a cavity of air injected at high speed under a surface equipped with dynamic motions and with a mesh overset. This effect produces localized areas under the hull with the presence of the air which in reality does not exist. This presence of the air could lead to a reduction of the drag with respect to experimental tests. In this case the effect is localized and produces a difference lower than $7 \%$.

Another two crucial parameters compared are the trim and the sinkage. Figure 11 shows the behavior of the trim of the model during the different velocities. The trend of the curves is similar, with peaks of the CFD model more marked than the experimental test. Trim prediction is always the most challenging issue because it depends not only on the pressure but also on its distribution and, in particular, in this case, it is strictly related to the wetted length. However, even if the trend tends to change about Fn 0.8, the maximum difference is lower than $10 \%$. In Figure 12 the sinkage comparison is reported, the two curves have the same trend.

The CFD results of this campaign confirm that the settings used for the Virtual Towing Tank allow having results very similar to experimental tests. The comparison highlights the same trend for the three different quantities reported. Another important physic quantity is the wetted surface of the boat. This quantity is not a result of the experimental tests, but it can be evaluated with CFD simulations. Figure 13 shows the ratio between the wetted surface area in static condition and during the corresponding speed. The graph highlights a drastic decrease of the wetted surface between 0.7 and 1 of the Froude number. In this condition, the wetted surface is about $65 \%$ of the static one. At the Froude number of 0.7 , the hull starts to planing so there is a decreasing of the wetted surface. The complete planing is reached at a Froude number of about 1.0. 


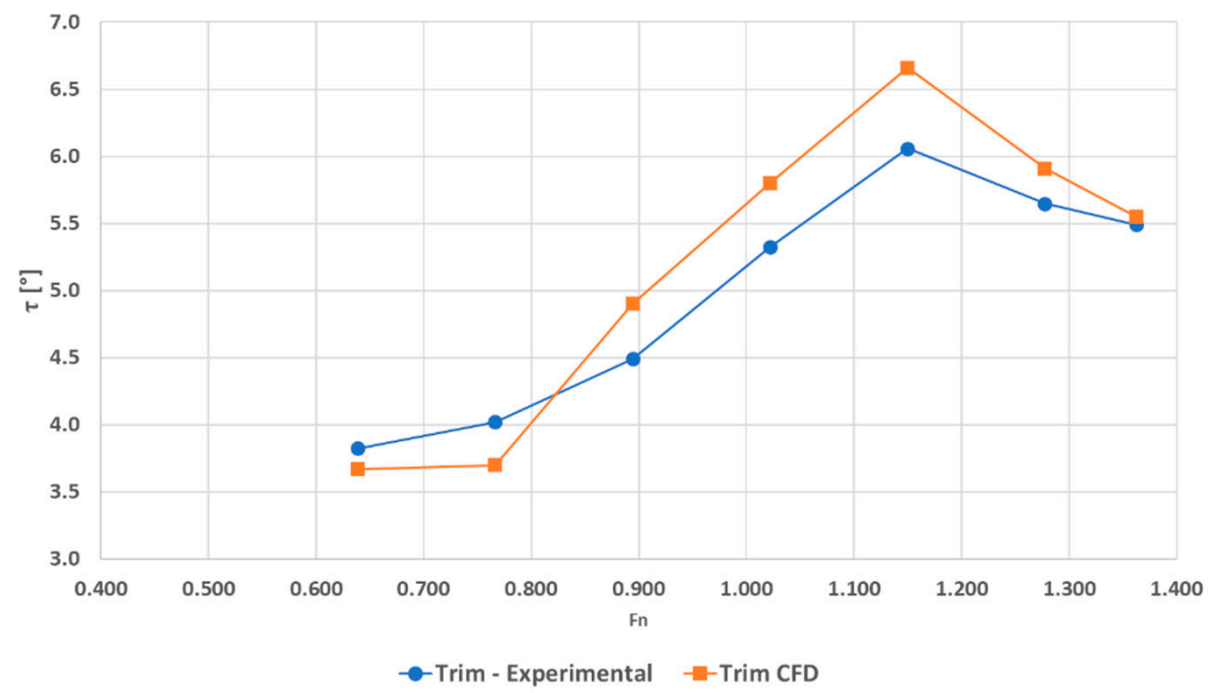

Figure 11. Trim comparison.

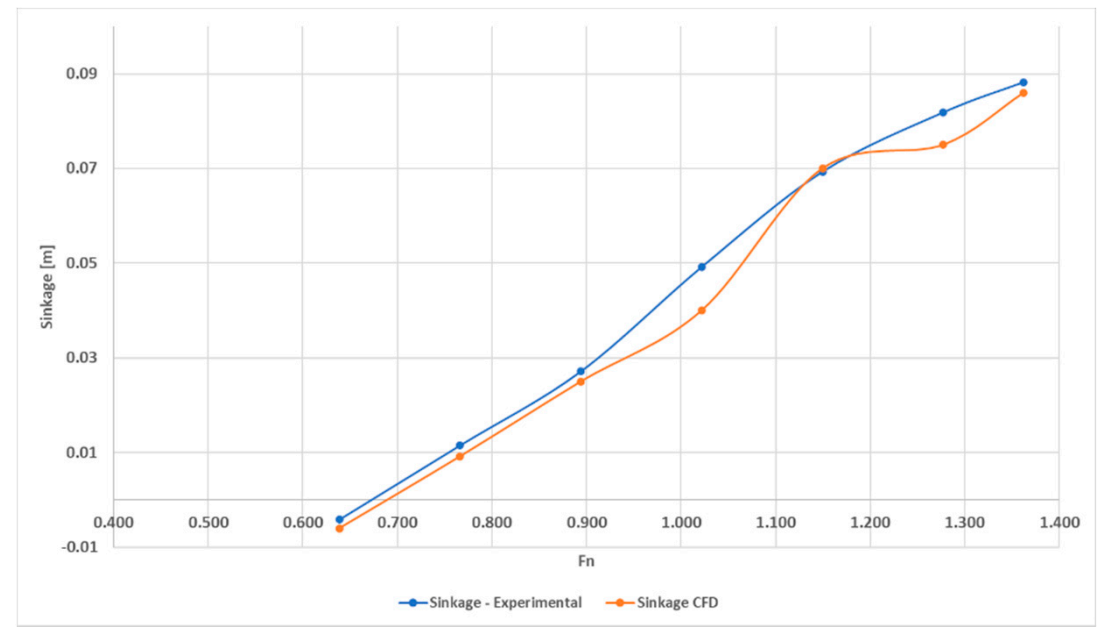

Figure 12. Sinkage comparison.

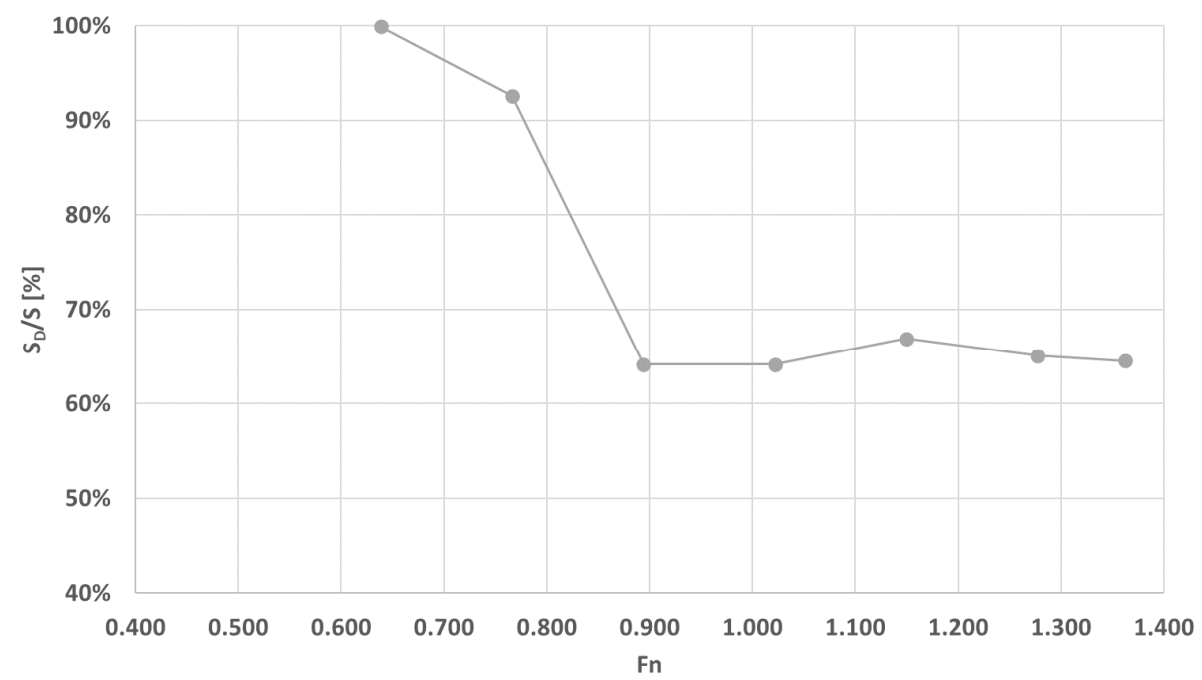

Figure 13. Wetted surface ratio-Dynamic/Static surface. 
At the last value of this campaign of velocity, as mentioned above, an uncertainty analysis was conducted in order to evaluate the influence of the grid to the final result. At the value of Fn of 1.36, three different meshes were investigated with the number of cells in ratio of 1.4 (as suggested by ITTC [35]). Table 5 shows the results of the physical quantities investigated to the three different meshes. For all the parameters under investigation, the method used suggests a monotonic convergence (Table 6). Thanks to the monotonic convergence, the safety factor of the Richardson expression (6) as suggested by Stern [36] can be equal to 1 . The same table shows that the maximum uncertainty is about $5.1 \%$ for the mesh used in this campaign of simulations. The maximum uncertainty is for the value of drag.

Table 5. Number of elements and different result for different meshes.

\begin{tabular}{cccc}
\hline Parameter & Fine & Medium & Coarse \\
\hline Elements & $2,345,723$ & $1,663,633$ & $1,184,081$ \\
$D$ & 281 & 293 & 315 \\
$\tau_{\text {CFD }}[\mathrm{deg}]$ & 5.55 & 5.72 & 6.01 \\
DTBow $_{\text {CFD }}[\mathrm{m}]$ & 0.086 & 0.091 & 0.102 \\
$\mathrm{~S}_{\text {DYN }}\left[\mathrm{m}^{2}\right]$ & 1.408 & 1.443 & 1.502 \\
\hline
\end{tabular}

Table 6. Uncertainty analysis.

\begin{tabular}{cccccc}
\hline \multicolumn{7}{c}{ Medium/Fine } & Coarse/Medium & & & \\
\hline Parameter & $\varepsilon_{n 21}$ & $\varepsilon_{\boldsymbol{n} 32}$ & $\mathbf{R}_{\mathrm{G}}$ & $\mathbf{P}_{\mathbf{G}}$ & $\mathbf{U}[\%]$ \\
\hline $\mathrm{D}$ & 12 & 22 & 0.55 & 1.75 & 5.1 \\
$\tau_{\mathrm{CFD}}$ & 0.17 & 0.29 & 0.59 & 1.54 & 4.3 \\
DTBow $_{\mathrm{CFD}}$ & -0.005 & -0.011 & 0.45 & 2.28 & 4.8 \\
$\mathrm{~S}_{\mathrm{DYN}}$ & -0.035 & -0.06 & 0.59 & 1.51 & 3.6 \\
\hline
\end{tabular}

\subsection{The Second Campaign of Simulation}

In this part of the simulation, for each number of Froude simulated in the first campaign, the virtual tests were performed adding the air injection. Also in this case, the numerical simulations were compared with experimental tests and in adding, thanks to the Virtual Towing tank, the wetted surface was reported for each condition of air flow.

Figure 14 shows the first two flow rates with the relative curves of experimental tests. In both cases, the CFD results of air injection have a trend lower than experimental tests. In general, the air injection to these flow rates produces a decrease of resistance in the magnitude of $1 \%$ on average for the experimental tests. For CFD results, this decrease of resistance, on average, is in the magnitude of $5 \%$. The difference between experimental tests and numerical simulations is lower than $15 \%$ in all the points. The difference between experimental tests and numerical simulations could be caused by the great mixture of air and water to these values of flow rate. The VoF scheme, with the HRIC model tends to underestimate the mix of air and water in the rails and underestimate the wetted surface, introducing a more positive effect on drag than experimental tests.

Thanks to CFD it is possible to evaluate the differences in terms of reduction of the wetted surface with the air injection. The reduction of the wetted surface allows decreasing the frictional resistance of the model. On average, the reduction of wetted surface for $5500 \mathrm{~L} / \mathrm{min}$ and $6500 \mathrm{~L} / \mathrm{min}$ is about $60 \%$. Figure 15 shows the trend to different velocities for both the flow rates. The first two flow rates investigated suggest that no great difference there is between $5500 \mathrm{~L} / \mathrm{min}$ and $6500 \mathrm{~L} / \mathrm{min}$. The air under the hull probably is not entirely developed and the effect in terms of drag is very low in both flow rates. 

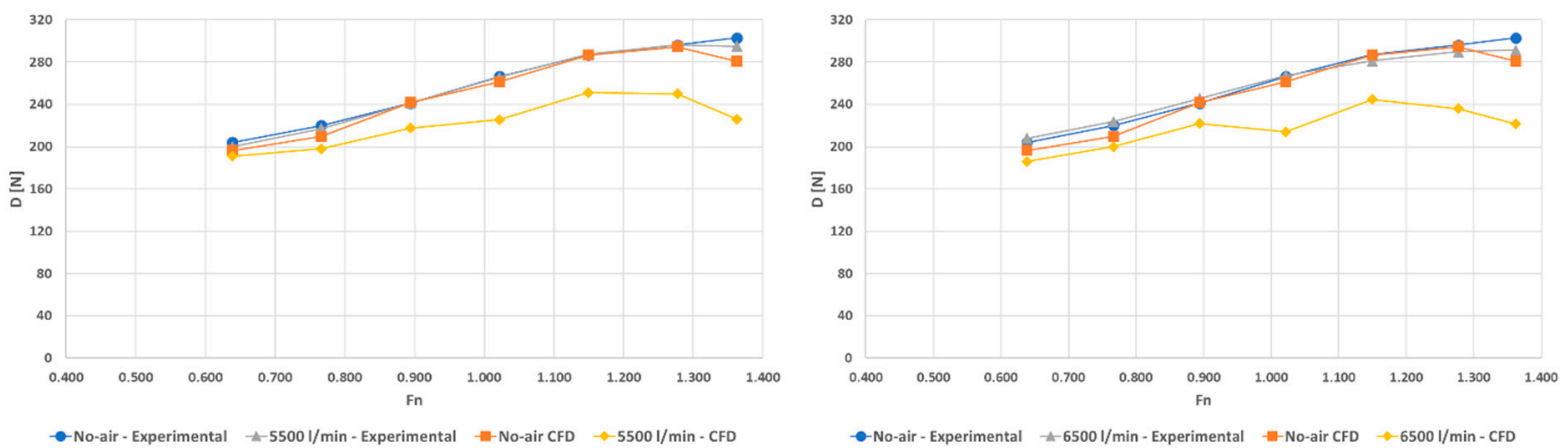

Figure 14. Experimental and CFD results to air injection $5500 \mathrm{~L} / \mathrm{min}$ and $6500 \mathrm{~L} / \mathrm{min}$.
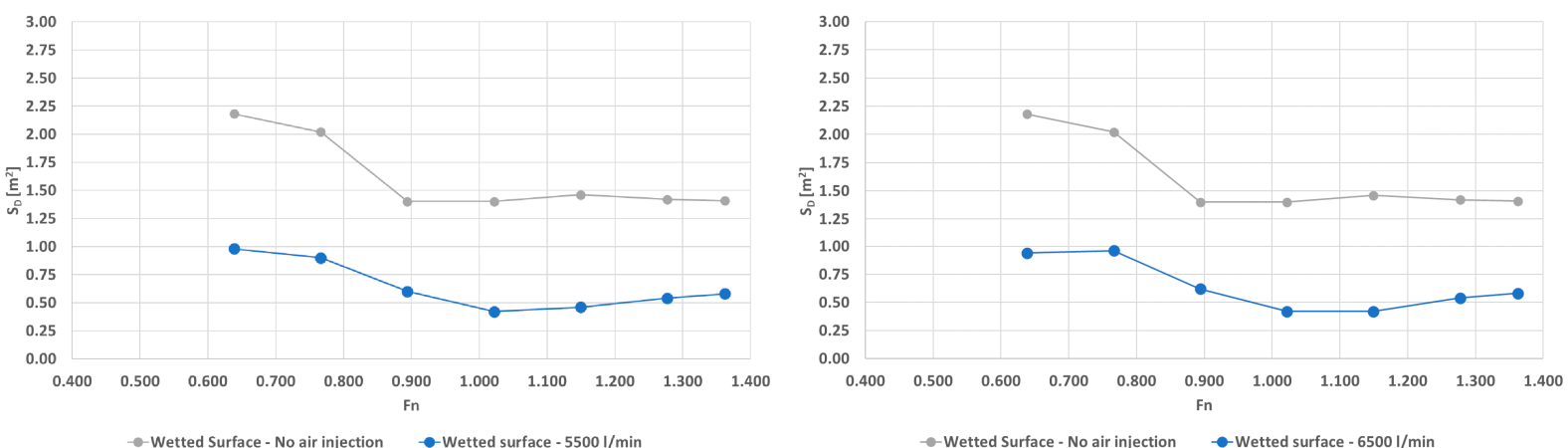

Figure 15. Wetted surface comparison-Air $(5500 \mathrm{~L} / \mathrm{min}$ and $6500 \mathrm{~L} / \mathrm{min})$ and No air.

Figure 16 shows the drag curves for $7500 \mathrm{~L} / \mathrm{min}$ and $8500 \mathrm{~L} / \mathrm{min}$ flow rates and the relative ones without air injection. In both cases, the CFD results of air injection have a trend lower than experimental tests. In general, the air injection to flow rate of $7500 \mathrm{~L} / \mathrm{min}$ produces a decrease of resistance in the magnitude of $2 \%$ on average for the experimental tests. For CFD results, this decrease is about $7 \%$. In the case of $8500 \mathrm{~L} / \mathrm{min}$, the reduction is about $8 \%$ for experimental tests and $11 \%$ for CFD results. The difference between experimental tests and numerical simulations is lower than $15 \%$ in all the points.
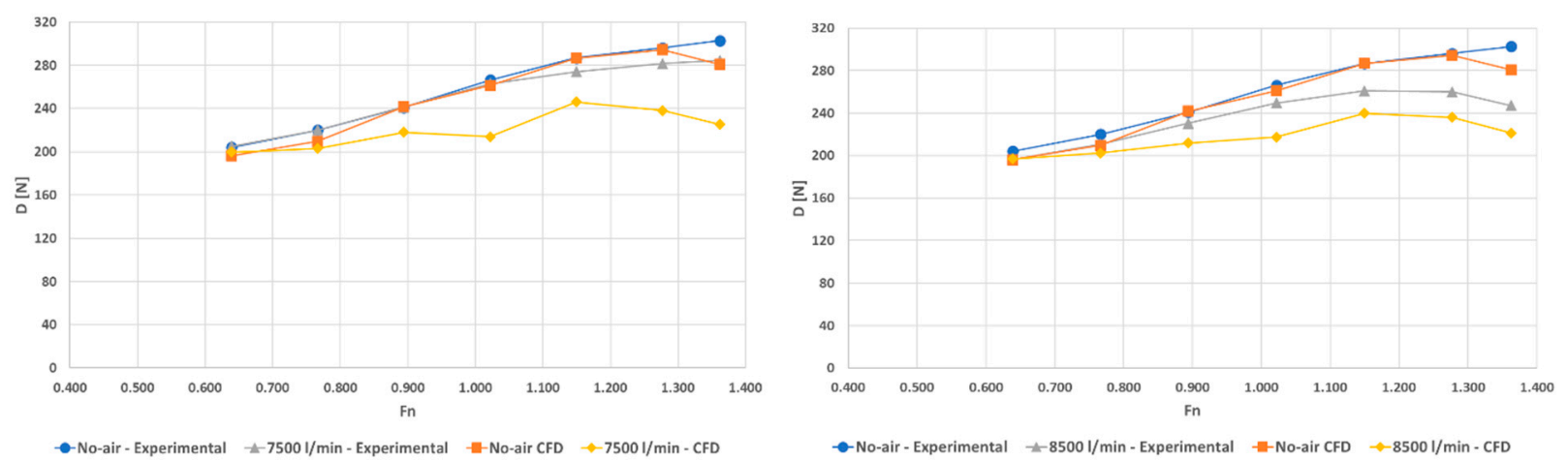

Figure 16. Experimental and CFD results to air injection $7500 \mathrm{~L} / \mathrm{min}$ and $8500 \mathrm{~L} / \mathrm{min}$.

Figure 17 shows the wetted surface at different Fn for flow rates of 7500 and $8500 \mathrm{~L} / \mathrm{min}$. The decrease of the wetted surface area is respectively $62 \%$ and $65 \%$. To the flow rate of $8500 \mathrm{~L} / \mathrm{min}$ the decrease of drag is appreciable in experimental tests and in CFD simulations. The flow of air under the hull starts to cover a higher percentage of bottom of the hull. This value of flow rate seems to be the turning point, lower than this value the effects are negligible. 

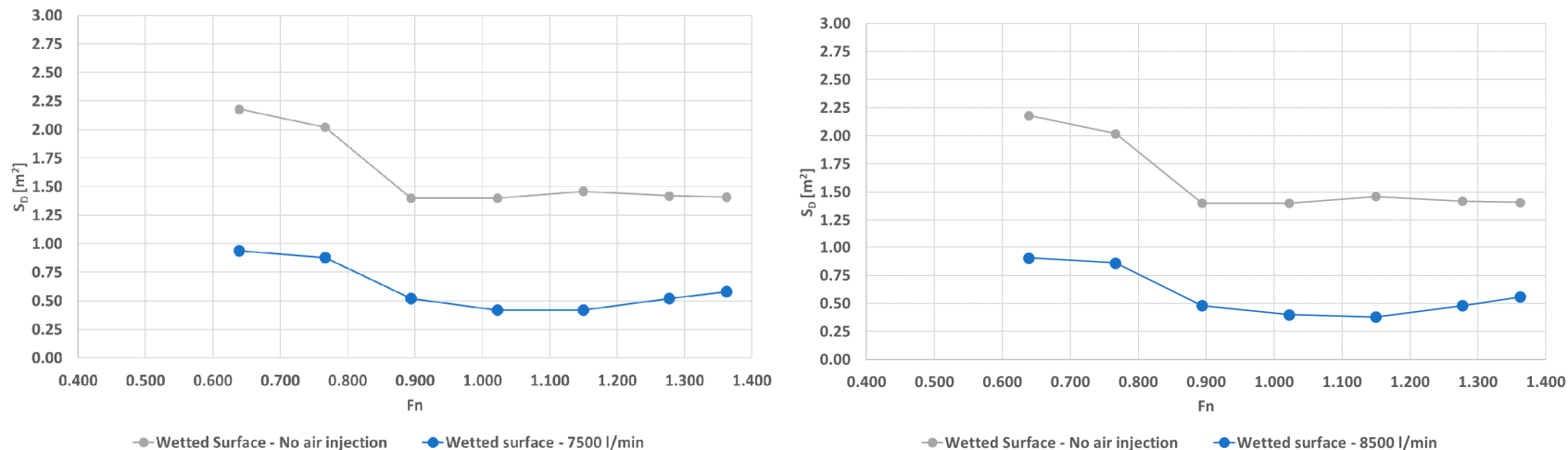

Figure 17. Wetted surface comparison-Air $(7500 \mathrm{~L} / \mathrm{min}$ and $8500 \mathrm{~L} / \mathrm{min})$ and No air.

Figure 18 shows the drag curves for $9500 \mathrm{~L} / \mathrm{min}$ and 10,500 L/min flow rates and the relative ones without air injection. In this case, the CFD curves have a trend lower than the experimental ones, but the difference is reduced to lower than $10 \%$. In general, the air injection to flow rate of $9500 \mathrm{~L} / \mathrm{min}$ produces a decrease of resistance in the magnitude of $11 \%$ on average for the experimental tests. For CFD results, this decrease is about $15 \%$. For a flow rate of $10,500 \mathrm{~L} / \mathrm{min}$ the decrease is $13 \%$ for the experimental test and $17 \%$ for CFD results.
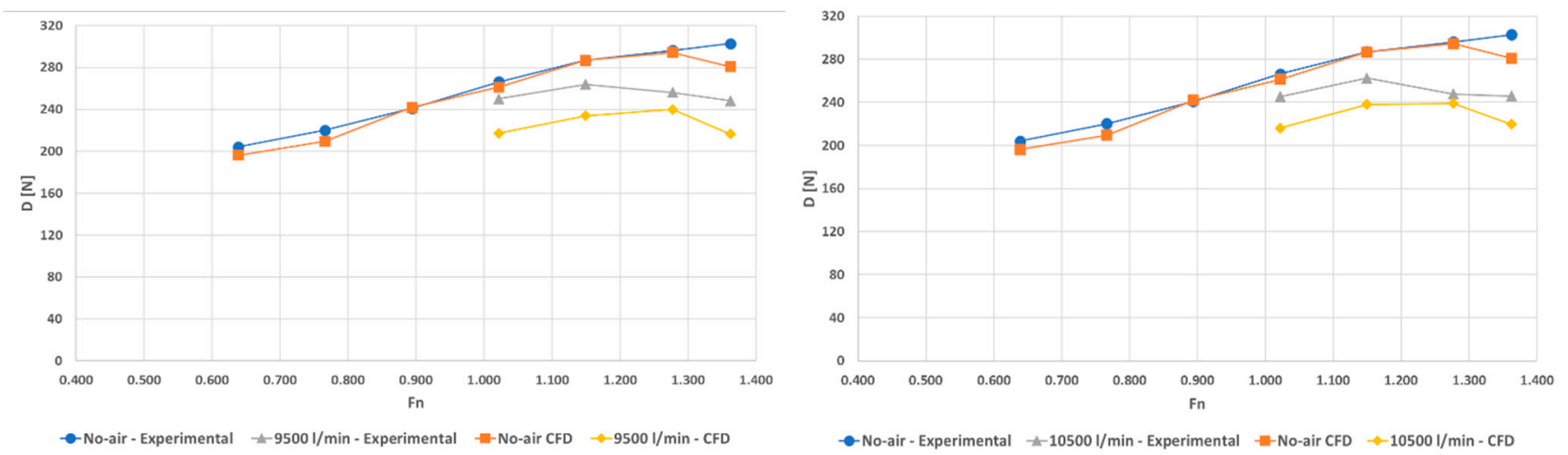

Figure 18. Experimental and CFD results to air injection $9500 \mathrm{~L} / \mathrm{min}$ and 10,500 L/min.

Comparing to similar experiences carried out on the same hull but without the presence of the rails (i.e., [31,32]), in this study, the agreement between experimental and numerical data is lower for all the ventilated cases. This result probably depends on the difficulty of the interface models used to predict the real ventilated hull surface. In particular, the HRIC scheme tends to underestimate the air-water mixing in correspondence of hull discontinuity, and consequently to overestimate the ventilated surface, leading a reduction in the drag prediction. This numerical phenomenon must be properly evaluated as it was not a problem for flat bottom hulls.

Figure 19 shows the trend to different velocities for flow rates to 9500 and 10,500 L/min. The decrease of the wetted surface area is respectively $68 \%$ and $69 \%$. The flow rates are the higher ones and the air under the hull cover almost the entire bottom.

Figure 20 shows the trend of drag reduction to different flow rates at the same Fn. The curves show that with the increase of the Froude number the curves tend to an high level of reduction of resistance. The curves show that to Fn number of 0.639 and 0.766 , the decrease of resistance is almost equal to zero and also with the increase of the flow rates this behaviour remains the same. 

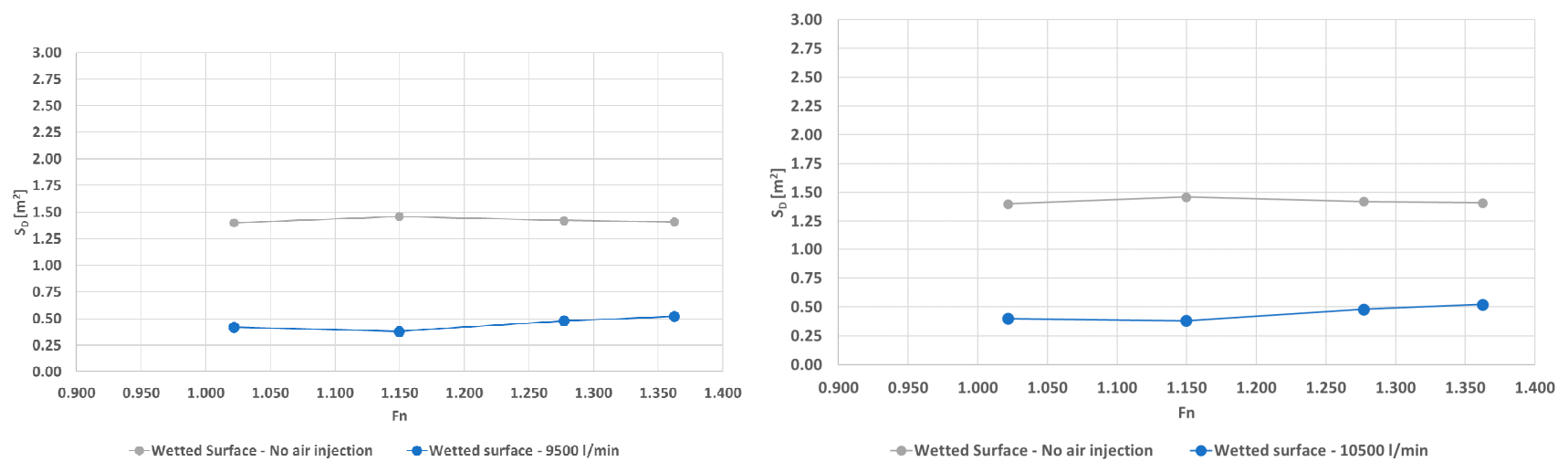

Figure 19. Wetted surface comparison-Air (9500 L/min and 10,500 L/min) and No air.

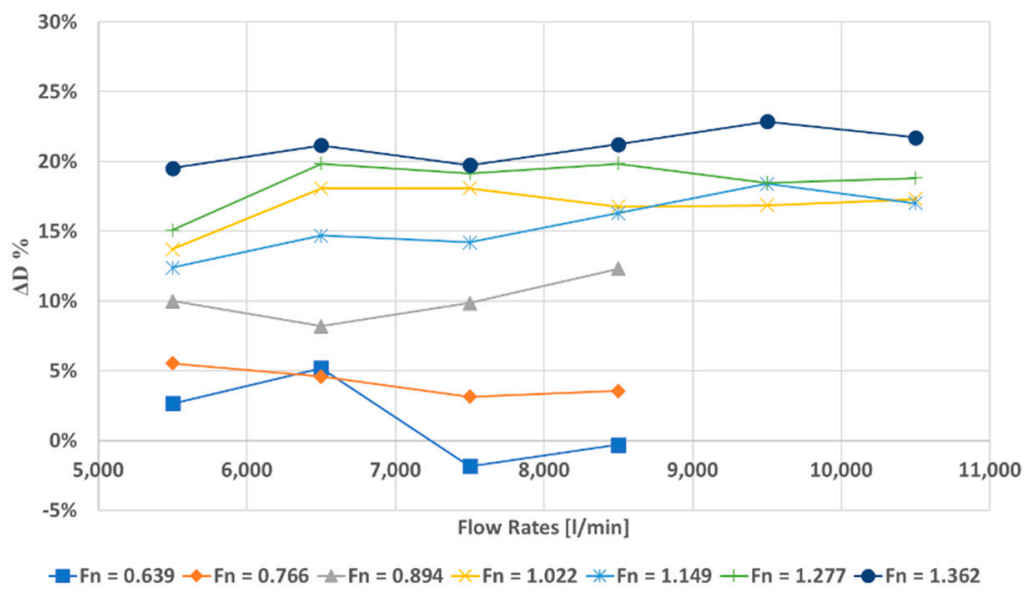

Figure 20. Reduction of resistance vs flow rate to the same Fn.

To the Fn number of 0.894 the starting point of increase of percentage reduction is the flow rate of $6500 \mathrm{~L} / \mathrm{min}$. This starting point it is also visible for the Froude number equal to 1.149 but it is translated to the flow rate of $7500 \mathrm{~L} / \mathrm{min}$. To the highest values of Froude number, the curves seem flat and the flow rates does not affect the reduction of drag. To these values of Fn, there is not great need to push the flow rate until to 10,500 in order to obtain the desidered effects.

The advantage of this hull grows with increasing speed, up to a peak reduction of $24 \%$ (at Fn 1.362 and $9500 \mathrm{~L} / \mathrm{min}$ ). For a speed of $\mathrm{Fn}<1$, the ventilation is not particularly effective and tends not to lead to benefits. For Fn $\geq 1$, on the other hand, the benefits grow rapidly and the most advantageous air flow rates are those at $9500 \mathrm{~L} / \mathrm{min}$, above which the gain is reduced again.

In Figure 21 are reported all the wetted surfaces, for each Fn, in three different conditions, respectively, the no-air condition and the minimum and maximum tested flow rates. In the pictures, the water is represented by the color red and the air by the color blue. The figure highlights that to all the Froude numbers, the flow rate of $5500 \mathrm{~L} / \mathrm{min}$ is not enough to wet the bottom of the hull completely. At this flow rate, for little Froude numbers, the air tends to escape from the sides, while for high Froude numbers there is a tendency of the air to be dragged up to the stern, remaining at the center of the boat. At the same time, at high speeds, air and water are less mixed. For this reason, for the Froude number higher than 1.27, the air does not escape from the sides of the boat and on the bilge area there is a channel of a stable water. From the same figure, it is possible to see that the ideal condition seems to be reached with the condition of 10,500 L/min at the Froude number of 1.15. In this case, the bottom of the hull and the area around the bilge are almost wholly wetted by the air without mixing with water. 


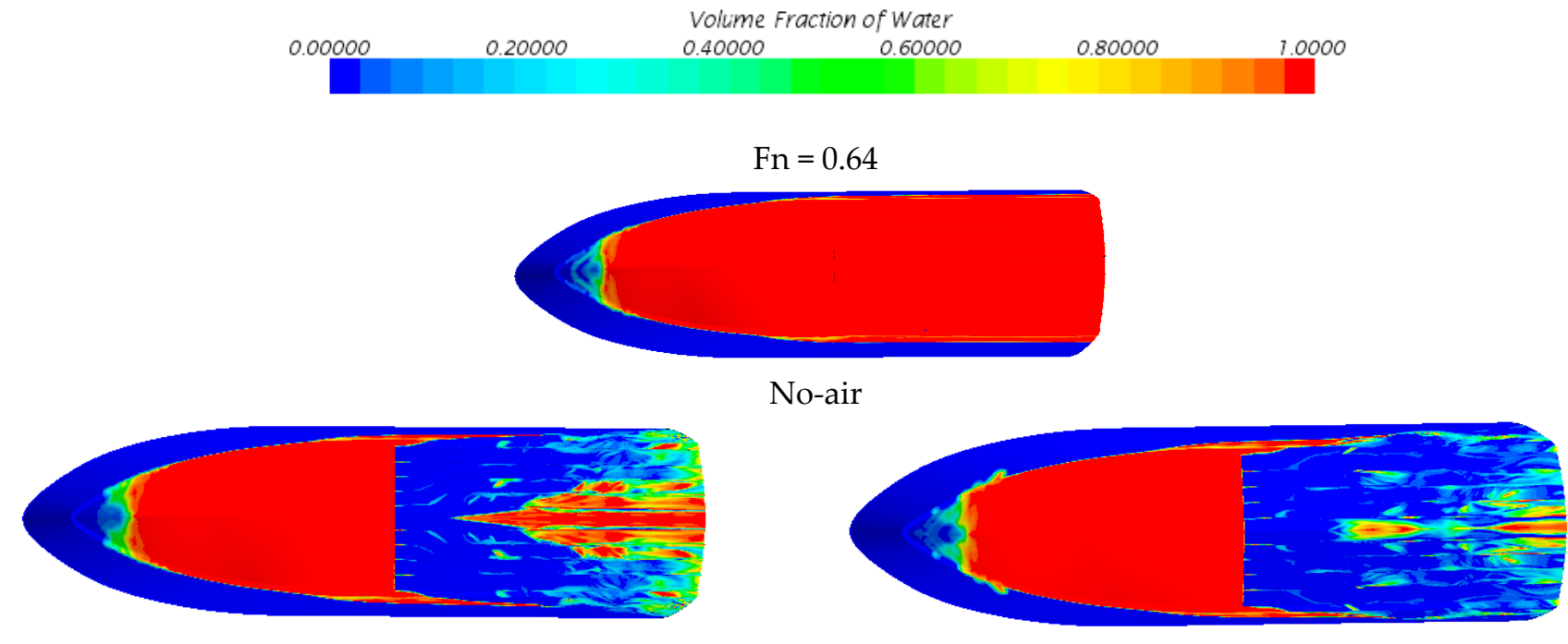

Flow rate $5500 \mathrm{~L} / \mathrm{min}$

Flow rate $10,500 \mathrm{~L} / \mathrm{min}$

$$
\mathrm{Fn}=0.76
$$

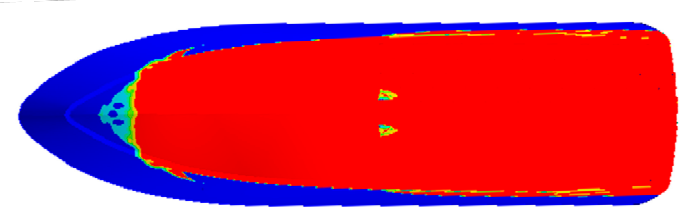

No-air

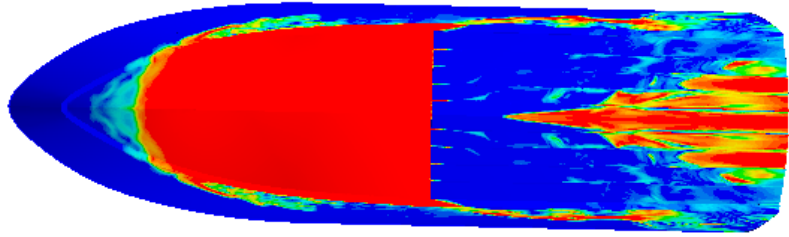

Flow rate $5500 \mathrm{~L} / \mathrm{min}$

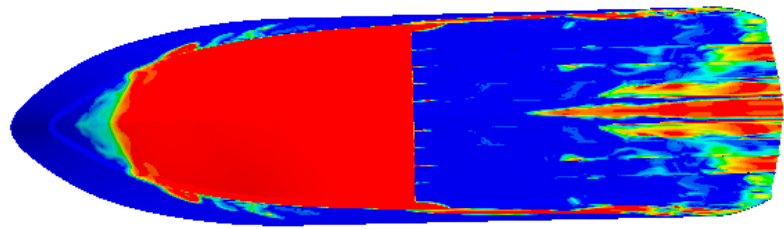

Flow rate $10,500 \mathrm{~L} / \mathrm{min}$

$$
\mathrm{Fn}=0.89
$$

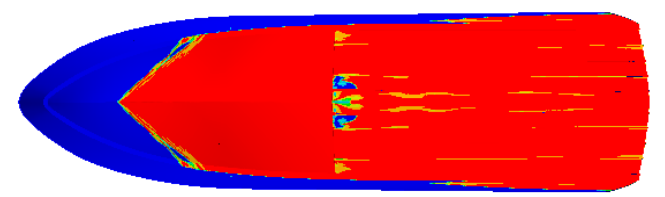

No-air

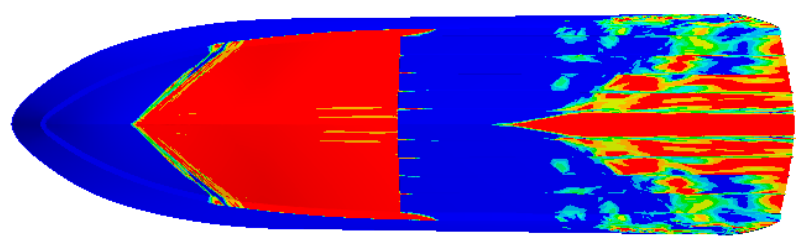

Flow rate $5500 \mathrm{~L} / \mathrm{min}$

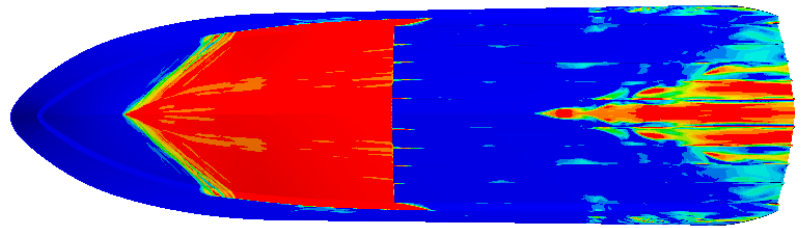

Flow rate $10,500 \mathrm{~L} / \mathrm{min}$

Figure 21. Cont. 


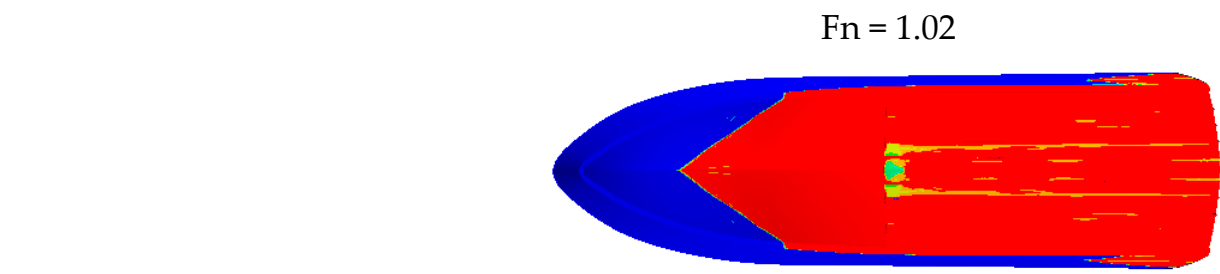

No-air

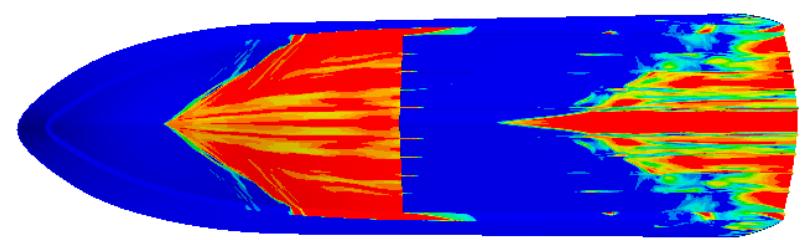

Flow rate $5500 \mathrm{~L} / \mathrm{min}$

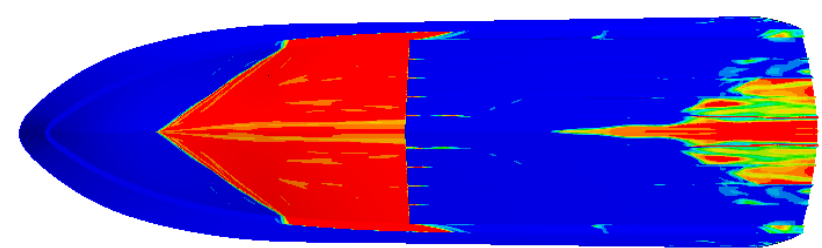

Flow rate $10,500 \mathrm{~L} / \mathrm{min}$

$\mathrm{Fn}=1.15$

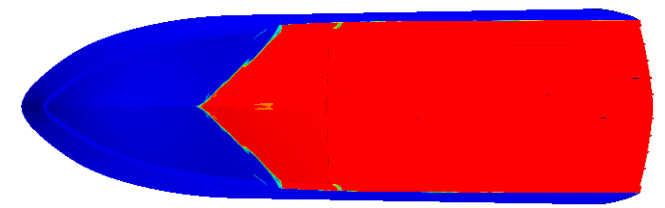

No-air

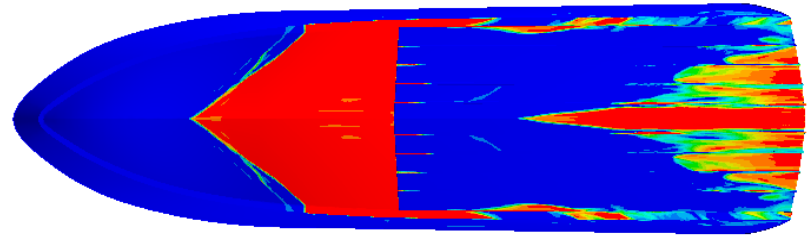

Flow rate $5500 \mathrm{~L} / \mathrm{min}$

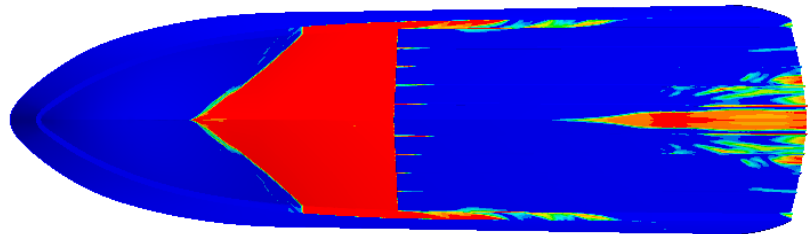

Flow rate $10,500 \mathrm{~L} / \mathrm{min}$

$\mathrm{Fn}=1.27$

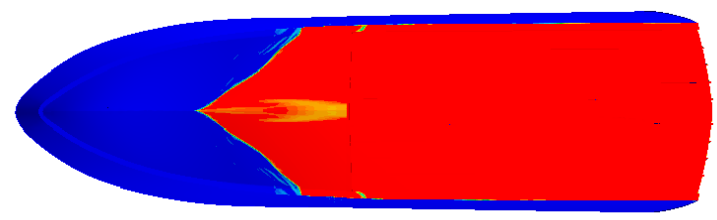

No-air

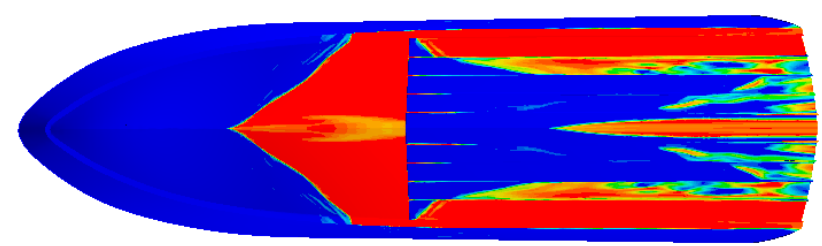

Flow rate $5500 \mathrm{~L} / \mathrm{min}$

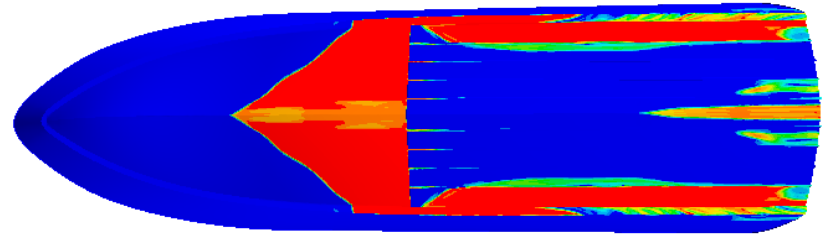

Flow rate $10,500 \mathrm{~L} / \mathrm{min}$

Figure 21. Cont. 


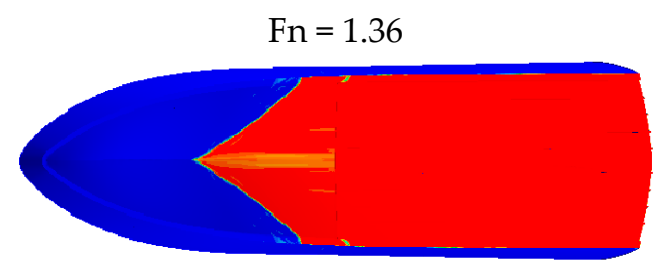

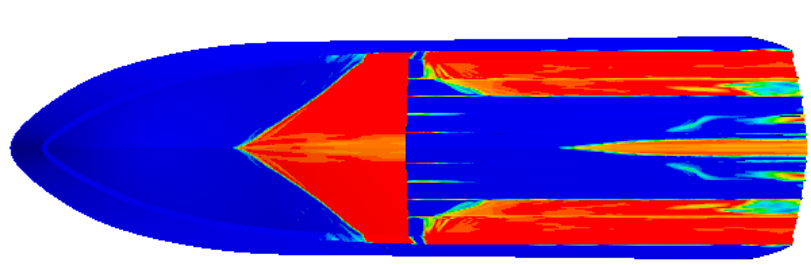

Flow rate $5500 \mathrm{~L} / \mathrm{min}$

No-air

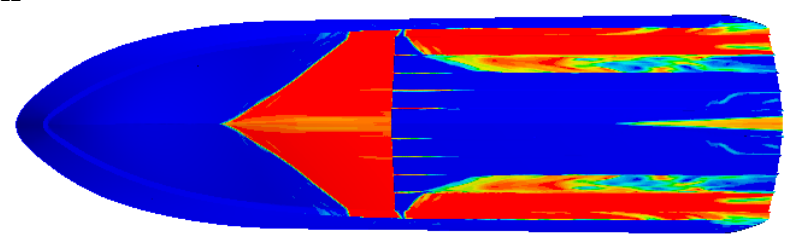

Flow rate $10,500 \mathrm{~L} / \mathrm{min}$

Figure 21. Wetted surface in three different conditions: no-air and injection of the air to the minimum and maximum flow rate.

The longitudinal rails at low flow rates cannot retain the air and consequently are a disadvantage more than an advantage since they increase the wetted surface.

\section{Conclusions}

The experimental and numerical campaigns carried out on an ACS showed the high potentiality of the hull ventilation, also for planing hulls. The natural under pressure generates under the step, as in an airfoil lower surface, help the air to ventilate the hull without escaping too fast.

The hull reach a greatest advantage of about $24 \%$ of drag reduction. In the best conditions, it is clearly visible that the chain is wet (a sign that the air does not escape laterally) and that consequently the air channel completely fills the cavity up to the transom.

Event if it can be considered a good result, the rails under the hull have not been shown to give a great benefit compared to the hull without them. The idea for which they were designed, was that of channeling the flow of air towards the stern, limiting the lateral escaping, has proved to be ineffective. The airflow towards the stern in fact depends mainly on the Froude number. As Fn increases, the air tends to follow the travel direction, in the same way as the hull with the flat bottom [31]. On the contrary, the rails considerably increase the wet surface. The overall balance is therefore negative.

Even if the accordance between experimental and CFD results is good, the hull equipped with rails, compared to the flat ones showed in other papers, reveals a more significant error. This is probably due to greater difficulty in estimating the actual wetted surface in the area of the rails.

In this sense, the VoF scheme with the HRIC model, which well describes the wave surface into the air-water interface, tends to underestimate the mix of air and water in the rails and underestimate the wetted surface. Indeed, the real effect showed by experiments leads to the generation of microbubbles, instead of big, well-formed bubbles. The CFD campaign, therefore, showed that on this kind of boat, when the discontinuities under the hull increase, not only the hull has not great benefits in terms of drag reduction, but also that the numerical error increases.

The obtained results indicate interesting possibilities for future development in the study of biphasic phenomena under the hull, particularly in the presence of abrupt discontinuities. Different models than HRIC can be, in future, developed and applied to search for a better matching between experimental and numerical outcomes. 
Author Contributions: Conceptualization, F.C. and F.S.; methodology, F.C.; software, F.S.; validation, F.S., F.T., and D.M.; data curation, F.T. and D.M.; writing-original draft preparation, F.S.; writingreview and editing, F.C.; supervision, F.C. All authors have read and agreed to the published version of the manuscript.

Funding: This work was partially supported by European Union (PON R\&C 2007-2013 and PON 2015-2020 ARS01_00334) funding. Authors wish to thank the personnel of Naples Towing Tank for the support during the experimental tests.

Institutional Review Board Statement: Not applicable.

Informed Consent Statement: Not applicable.

Data Availability Statement: The data presented in this study are available on request from the corresponding author.

Conflicts of Interest: The authors declare no potential conflicts of interest with respect to the research, authorship, and/or publication of this article.

\section{Nomenclature}

Definition

Overall Length

Waterline Length

Projected Chine Length

Waterline Beam

Projected Maximum Beam

Projected Beam at generic $X$ position

Projected Beam Transom

Deadrise Angle

Height of medium buttock line

Draught

Displacement

Total Resistance

Weight force

Longitudinal centre of gravity

Wetted surface Area

Dynamic Wetted Surface Without Air Injection

Dynamic Wetted Surface With Air Injection

Projected Area

Velocity of Ship

Velocity of Model

Froude number

Length of Ship

Length of Model

Scale

Number of Steps

Position of the step relative to the transom

Refinement ratio of the three meshes

Area Step

Number of nozzles

Dimensions-Basis $\times$ Height

Area of nozzles

Volumetric Flow Rate

\begin{tabular}{|c|c|}
\hline Symbol & Unit \\
\hline LOA & $\mathrm{m}$ \\
\hline LWL & $\mathrm{m}$ \\
\hline LP & $\mathrm{m}$ \\
\hline BWL & $\mathrm{m}$ \\
\hline $\mathrm{BPX}$ & $\mathrm{m}$ \\
\hline $\mathrm{BPC}$ & $\mathrm{m}$ \\
\hline $\mathrm{BPT}$ & $\mathrm{m}$ \\
\hline$\beta$ & $\circ$ \\
\hline HLM & $\mathrm{m}$ \\
\hline $\mathrm{T}$ & $\mathrm{m}$ \\
\hline$\Delta$ & $\mathrm{t}$ \\
\hline $\mathrm{R}_{\mathrm{T}}$ & $\mathrm{N}$ \\
\hline W & $\mathrm{N}$ \\
\hline$x_{G}$ & $\mathrm{~m}$ \\
\hline$S$ & $\mathrm{~m}^{2}$ \\
\hline$S_{D}$ & $\mathrm{~m}^{2}$ \\
\hline$S_{\text {DAir }}$ & $\mathrm{m}^{2}$ \\
\hline $\mathrm{AP}$ & $\mathrm{m}^{2}$ \\
\hline $\mathrm{V}_{\mathrm{S}}$ & $\mathrm{m} / \mathrm{s}$ \\
\hline $\mathrm{V}_{\mathrm{M}}$ & $\mathrm{m} / \mathrm{s}$ \\
\hline Fn & - \\
\hline $\mathrm{L}_{\mathrm{S}}$ & $\mathrm{m}$ \\
\hline $\mathrm{L}_{\mathrm{M}}$ & $\mathrm{m}$ \\
\hline$\lambda$ & - \\
\hline $\mathrm{N}_{\mathrm{ST}}$ & - \\
\hline $\mathrm{L}_{\mathrm{ST}}$ & $\mathrm{m}$ \\
\hline $\mathrm{r}_{\mathrm{K}}$ & \\
\hline $\mathrm{S}_{\mathrm{ST}}$ & $\mathrm{m}^{2}$ \\
\hline $\mathrm{N}_{\mathrm{IN}}$ & - \\
\hline $\mathrm{B}_{\mathrm{IN}} \times \mathrm{H}_{\mathrm{IN}}$ & $\mathrm{m} \times \mathrm{m}$ \\
\hline $\mathrm{S}_{\mathrm{IN}}$ & $\mathrm{m}^{2}$ \\
\hline $\mathrm{Q}$ & $\mathrm{m}^{3} / \mathrm{s}$ \\
\hline
\end{tabular}

\section{References}

1. Lewis, E.V. Principles of Naval Architecture; The Society of Naval Architects and Marine Engineers: Jersey City, NJ, USA, 1988; ISBN 0-939773-01-5.

2. Larsson, L.; Raven, H. Ship Resistance and Flow; Paulling, J.R., Ed.; The Society of Naval Architects and Marine Engineers: Jersey City, NJ, USA, 2010; ISBN 978-0-939773-76-3. 
3. Papanikolaou, A. Developments and Potential of Advanced Marine Vehicles Concepts. Bull. Kansai Soc. Nav. Achitects 2002, 55, 50-54.

4. Matveev, K. On the Limiting Parameters of Artificial Cavitation. Ocean Eng. 2003, 30, 1179-1190. [CrossRef]

5. Cucinotta, F.; Nigrelli, V.; Sfravara, F. A Preliminary Method for the Numerical Prediction of the Behavior of Air Bubbles in the Design of Air Cavity Ships. In Advances in Mechanical Engineering; J.B. Metzler: Stuttgart, Germany, 2017; pp. 509-516.

6. Kodama, Y.; Kakugawa, A.; Takahashi, T.; Sugiyama, T. Drag Reduction of Ships by Microbubbles. In Proceedings of the 24th Symposium on Naval Hydrodynamics, Fukuoka, Japan, 8-13 July 2002.

7. Savitsky, D. Hydrodynamic Design of Planing Hulls. Mar. Technol. SNAME News 1964, 1, 71-95. [CrossRef]

8. Dashtimanesh, A.; Tavakoli, S.; Sahoo, P. A Simplified Method to Calculate Trim and Resistance of a Two-Stepped Planing Hull. Ships Offshore Struct. 2017, 12, S317-S329. [CrossRef]

9. Dashtimanesh, A.; Roshan, F.; Tavakoli, S.; Kohansal, A.; Barmala, B. Effects of Step Configuration on Hydrodynamic Performance of One- and Doubled-Stepped Planing Flat Plates: A Numerical Simulation. Proc. Inst. Mech. Eng. Part M J. Eng. Marit. Environ. 2019, 234, 181-195. [CrossRef]

10. Dashtimanesh, A.; Tavakoli, S.; Kohansal, A.; Khosravani, R.; Ghassemzadeh, A. Numerical Study on a Heeled One-Stepped Boat Moving Forward in Planing Regime. Appl. Ocean Res. 2020, 96, 102057. [CrossRef]

11. De Marco, A.; Mancini, S.; Miranda, S.; Scognamiglio, R.; Vitiello, L. Experimental and Numerical Hydrodynamic Analysis of a Stepped Planing Hull. Appl. Ocean Res. 2017, 64, 135-154. [CrossRef]

12. Bilandi, R.N.; Dashtimanesh, A.; Tavakoli, S. Development of a 2D+T Theory for Performance Prediction of Double-Stepped Planing Hulls in Calm Water. Proc. Inst. Mech. Eng. Part M J. Eng. Marit. Environ. 2018, 233, 886-904. [CrossRef]

13. Bilandi, R.N.; Dashtimanesh, A.; Tavakoli, S. Hydrodynamic Study of Heeled Double-Stepped Planing Hulls using CFD and 2D+T Method. Ocean Eng. 2020, 196, 106813. [CrossRef]

14. Bilandi, R.N.; Vitiello, L.; Mancini, S.; Nappo, V.; Roshan, F.; Tavakoli, S.; Dashtimanesh, A. Calm-Water Performance of a Boat with two Swept Steps at High-Speeds: Laboratory Measurements and Mathematical Modeling. Procedia Manuf. 2020, 42, 467-474. [CrossRef]

15. Lee, E.; Pavkov, M.; McCue-Weil, L. The Systematic Variation of Step Configuration and Displacement for a Double-Step Planing Craft. J. Ship Prod. Des. 2014, 30, 89-97. [CrossRef]

16. Taunton, D.J.; Hudson, D.A.; Shenoi, R.A. Characteristics of a Series of High Speed Hard Chine Planing Hulls-Part 1: Performance in Calm Water. Trans. R. Inst. Nav. Archit. Part B Int. J. Small Cr. Technol. 2010, 152. [CrossRef]

17. Butuzov, A.A.; Vasin, A.I.; Drozdov, A.L.; Ivanov, A.N.; Kalyuzhny, V.G.; Matveev, I.I.; Ruzanov, V.E. Full-Scale Trials of a Boat with an Air Cavity. Shipbuild. Probl. 1988, 28, 45-51.

18. Mäkiharju, S.A.; Elbing, B.R.; Wiggins, A.; Schinasi, S.; Vanden-Broeck, J.-M.; Perlin, M.; Dowling, D.R.; Ceccio, S.L. On the Scaling of Air Entrainment from a Ventilated Partial Cavity. J. Fluid Mech. 2013, 732, 47-76. [CrossRef]

19. Matveev, K.I. Two-Dimensional Modeling of Stepped Planing Hulls with Open and Pressurized Air Cavities. Int. J. Nav. Arch. Ocean Eng. 2012, 4, 162-171. [CrossRef]

20. Matveev, K.I. Three-Dimensional Wave Patterns in Long Air Cavities on a Horizontal Plane. Ocean Eng. 2007, 34, 1882-1891. [CrossRef]

21. Butterworth, J.; Atlar, M.; Shi, W. Experimental Analysis of an Air Cavity Concept Applied on a Ship Hull to Improve the Hull Resistance. Ocean Eng. 2015, 110, 2-10. [CrossRef]

22. Cucinotta, F.; Guglielmino, E.; Sfravara, F. An Experimental Comparison between Different Artificial Air Cavity Designs for a Planing Hull. Ocean Eng. 2017, 140, 233-243. [CrossRef]

23. Wang, L.; Huang, B.; Qin, S.; Cao, L.; Fang, H.; Wu, D.; Li, C. Experimental Investigation on Ventilated Cavity Flow of a Model Ship. Ocean Eng. 2020, 214, 107546. [CrossRef]

24. Barbaca, L.; Pearce, B.W.; Ganesh, H.; Ceccio, S.L.; Brandner, P.A. On the Unsteady Behaviour of Cavity Flow over a TwoDimensional Wall-Mounted Fence. J. Fluid Mech. 2019, 874, 483-525. [CrossRef]

25. Qin, S.; Wu, Y.; Wu, D.; Hong, J. Experimental Investigation of Ventilated Partial Cavitation. Int. J. Multiph. Flow 2019, 113, 153-164. [CrossRef]

26. Cao, L.; Karn, A.; Arndt, R.E.A.; Wang, Z.; Hong, J. Numerical Investigations of Pressure Distribution Inside a Ventilated Supercavity. J. Fluids Eng. 2016, 139, 021301. [CrossRef]

27. Begovic, E.; Bertorello, C.; Mancuso, A.; Saporito, A. Sailing Dinghy Hydrodynamic Resistance by Experimental and Numerical Assessments. Ocean Eng. 2020, 214, 107458. [CrossRef]

28. Saporito, A.; Persson, A.; Larsson, L.; Mancuso, A. A New Systematic Series of Foil Sections with Parallel Sides. J. Mar. Sci. Eng. 2020, 8, 677. [CrossRef]

29. Cirello, A.; Cucinotta, F.; Ingrassia, T.; Nigrelli, V.; Sfravara, F. Fluid-Structure Interaction of Downwind Sails: A New Computational Method. J. Mar. Sci. Technol. 2019, 24, 86-97. [CrossRef]

30. Cella, U.; Cucinotta, F.; Sfravara, F. Sail Plan Parametric CAD Model for an A-Class Catamaran Numerical Optimization Procedure using Open Source Tools; Springer: Cham, Switzerland, Basel, Switzerland; 2017.

31. Cucinotta, F.; Guglielmino, E.; Sfravara, F.; Strasser, C. Numerical and Experimental Investigation of a Planing Air Cavity Ship and its Air Layer Evolution. Ocean Eng. 2018, 152, 130-144. [CrossRef] 
32. Cucinotta, F.; Guglielmino, E.; Sfravara, F. A Critical CAE Analysis of the Bottom Shape of a Multi Stepped Air Cavity Planing Hull. Appl. Ocean Res. 2019, 82, 130-142. [CrossRef]

33. Cucinotta, F.; Guglielmino, E.; Sfravara, F. Life Cycle Assessment in Yacht Industry: A Case Study of Comparison between Hand Lay-Up and Vacuum Infusion. J. Clean. Prod. 2017, 142, 3822-3833. [CrossRef]

34. Siemens. Simcenter STAR-CCM+ Documentation; Granite Park One; Siemens: Plano, TX, USA, 2020.

35. ITTC. Uncertainty Analysis in CFD Verification and Validation Methodology and Procedures; Ocean Technology Laboratory COPPE/UFRJ-Federal University of Rio de Janeiro: Rio de Janeiro, Brazil, 2011.

36. Stern, F.; Wilson, R.V.; Coleman, H.W.; Paterson, E.G. Comprehensive Approach to Verification and Validation of CFD Simulations-Part 1: Methodology and Procedures. J. Fluids Eng. 2001, 123, 793-802. [CrossRef]

37. Samuel; Kim, D.J.; Fathuddiin, A.; Zakki, A.F. A Numerical Ventilation Problem on Fridsma Hull Form Using an Overset Grid System. IOP Conf. Series Mater. Sci. Eng. 2021, 1096, 012041. [CrossRef]

38. Wang, H.; Zhu, R.; Huang, S.; Zha, L. Hydrodynamic Analysis of a Planing Hull in Calm Water Using Overset Mesh and Rigid Body Motion Method. In Proceedings of the 30th International Ocean and Polar Engineering Conference 2020 Sep 2. International Society of Offshore and Polar Engineers, Shanghai, China, 11-16 October 2020. 